\title{
Hogares y familias en México: una aproximación a su análisis mediante encuestas por muestreo
}

\section{Carlos Javier Echarri Cánovas*}

En el presente artículo se analizan algunas características de los hogares mexicanos utilizando una fuente de información poco explotada: los cuestionarios de hogar de las encuestas nacionales por muestreo.

Después de una revisión de la literatura sociodemográfica sobre los hogares y las familias, particularmente en Latinoamérica y México, en un primer apartado se analiza la jefatura de los hogares, tanto en lo que se refiere a su significado, como a sus determinantes. Por lo que toca al significado, se discute por una parte, si el atributo más importante de la jefatura es el de soporte económico o bien el de autoridad moral y por otra, su relación con el ciclo de vida. Esta discusión sirve como base para desarrrollar un primer análisis descriptivo de las características de los jefes de hogar, refiriéndose a la edad, el sexo, el estado civil, las reglas de residencia, la condición de actividad y el nivel de instrucción. A continuación se reúnen estas diferentes variables para proponer un modelo de determinantes de la jefatura de los hogares, el cual se ajusta para cada sexo mediante una regresión logística.

Posteriormente se analizan dos características de los hogares: su composición y las condiciones de vida en su interior. Por lo que toca a la composición, se estudia primero el tamaño de los hogares, enseguida a sus miembros, en función de parentesco con el jefe y la constitución de núcleos familiares, completos o incompletos.

Finalmente, respecto de las condiciones de vida de los hogares, la fuente de datos nos permite analizar la densidad de ocupación de las viviendas, por un lado, y la calidad de las mismas, por otro, refiriéndonos tanto a la infraestructura de servicios con los que se cuenta, como a las características físicas de la residencia.

\section{Introducción}

A pesar de que exista consenso dentro de la investigación sociodemográfica en considerar a la estructura familiar como una estructura dinámica que ejerce funciones de mediación entre los niveles individual y estructural, conservando, sin embargo, su propia especificidad (García, Muñoz y de Oliveira, 1982 y 1983; Lerner y Quesnel, 1982; Tabutin y Bartiaux, 1986), los estudios sobre la familia o el hogar son escasos. Recientemente, sin embar-

* Profesor-investigador del Centro de Estudios Demográficos y de Desarrollo Urbano de El Colegio de México. 
go, hemos asistido a un aumento en el interés por este tema, que empieza a ampliar nuestros conocimientos sobre las características de la familia o el hogar en México, los cuales son aún incompletos y fragmentarios, especialmente en lo que se refiere a su relación con otros fenómenos, tales como la migración, la participación laboral, la fecundidad, la nupcialidad o la salud.

Esto se debe a varias dificultades, entre las que pueden destacarse la ausencia de información adecuada, la complejidad del tema -que comienza con los problemas de definición-y las limitaciones propias de la demografía para abordarlo. Por lo que toca a las definiciones, Murdock (1949) considera a la familia como un grupo social caracterizado por la residencia común, la cooperación económica -basada en la división sexual del trabajo- y la reproducción, donde las relaciones sexuales entre dos miembros adultos unidos por el matrimonio son socialmente aprobadas; además, el grupo es responsable ante la sociedad de cuidar y de educar a los niños y constituye una unidad económica al menos en lo que concierne al consumo. Murdock le asigna a la familia, especialmente a la familia nuclear, cuatro funciones sociales distintivas y vitales: la sexual, la económica, la reproductiva y la educacional. Sin embargo, según algunos antropólogos, no existe ningún grupo social concreto que pueda ser identificado umiversalmente como "la familia". Las funciones sociales de la familia que se han supuesto como universales (la regulación sexual, la procreación, la socialización y la cooperación económica), no se encuentran en ciertos grupos familiares donde los padres no educan a sus hijos o donde el marido y la mujer se separan desde el momento de la ceremonia del matrimonio, sin que haya una cohabitación estable (Lira, 1977). De acuerdo con Malinowsky (1971), el único rasgo universal que distingue a la familia de otros grupos sociales es el llamado principio de legitimidad, según el cual en todas las sociedades hay una persona que tiene el papel de padre sociológico, encargado de la socialización de los hijos, como responsable, tutor o protector.

Las particularidades del tema de la familia hacen que la antropología, la etnología o la sociología sean más capaces que la demografía de dar cuenta de la complejidad y de la importante diversidad de la organización familiar en el mundo (Pilon, 1991). La demografía, con la especificidad de sus métodos, su naturaleza esencialmente cuantitativa y estadística y las características de la colecta de datos realizada casi siempre con otros fines, difícilmente puede considerar todos los niveles a la vez. La necesidad de contar con unidades de observación operacionales en los censos condujo a los demógrafos y a los estadígrafos a definir, a pesar 
de las imprecisiones, la noción de hogar-familia. El criterio de corresidencia y la referencia ideológica a la familia occidental restringida (nuclear) han sido determinantes en esta construcción (Lacombe y Lamy, 1989).

Partiendo de los estudios de la antropología social, y a veces usando sus métodos, los demógrafos finalmente han reconocido a la familia como un objeto de estudio en sí mismo, detallando incluso el campo de estudio de lo que se ha denominado demografía de la familia o del hogar. ${ }^{1}$ Esta no pretende englobar a la familia en su totalidad, ni sustituirse por otras disciplinas (particularm ente la sociología, la etnología o la antropología) (Pilon, 1991). Por otra parte, la restricción impuesta por la condición de la corresidencia limita fuertemente el estudio de la realidad familiar. Fenómenos tales como la cohabitación de personas no aparentadas, la ausencia de corresidencia de cónyuges y de hijos menores o aun el cuidado cotidiano de los hijos por parientes que viven en otras viviendas, son ejemplos de situaciones que escapan a la demografía de la familia.

En cambio, la demografía nos permite conocer ciertos aspectos de la organización familiar para grandes conjuntos de población, comparar ciertas características entre poblaciones o subpoblaciones y confrontar con la realidad las teorías de etnólogos y sociólogos, para quienes la naturaleza de las observaciones limita considerablemente el tamaño y la representatividad de las muestras consideradas. Respecto de las monografías familiares de los etnólogos, la demografía propone muestras representativas de gran tamaño (donde todo es recogido y no solamente los casos atípicos), ${ }^{2}$ la po-

1 Burch (1979) identifica los niveles siguientes dentro del campo de estudio de la demografía de la familia o del hogar: 1) el tamaño y la composición de los hogares, las familias y los grupos emparentados; 2) las variaciones entre países y regiones, así como entre subpoblaciones dentro de los países; 3) las variaciones en el tiempo: mutaciones seculares o cambios durante el ciclo de vida; 4) los determinantes demográficos (estructura por edad, fecundidad, mortalidad, nupcialidad y migración) y socio-económicos; 5) las consecuencias socio-económicas de los comportamientos; por ejemplo, las modalidades según las cuales son atendidos los niños, los roles de la edad y el sexo, las relaciones entre generaciones, el aislamiento y la dependencia de los ancianos y 6) las medidas demográficas de la estructura y de la evolución de la familia y el hogar.

2 Entendemos "atípicos" en el sentido estadístico. Una de las riquezas de los procedimientos antropológicos o de la observación microsocial es precisamente el hecho de poder tomar en cuenta casos excepcionales en lo que toca a su frecuencia; su función no es, sin embargo, la de probar una hipótesis sobre el comportamiento de una población, sino de ayudar a problematizar y a cuestionar los conceptos y generalizaciones con los que se trabaja en este ámbito de las ciencias sociales (Jelin, 1984: 651). 
sibilidad de controlar un gran número de variables y finalmente, la cuantificación.

Sin embargo, uno no puede conocer más que ciertos aspectos, sobre todo cuantitativos, de la estructura familiar; así, puede hablarse de la composición o de la complejidad de los hogares, pero al momento de tratar las estrategias familiares o los procesos de toma de decisiones, uno sólo puede observar los resultados de las acciones o los comportamientos que las produjeron. La racionalidad mediante la cual las familias (o los miembros individuales de las familias o los hogares) hacen la conexión entre los fines y los medios permanece como la gran incógnita de la demografía formal de la familia (Borsotti, 1984).

En lo que respecta a Latinoamérica, la región puede ser caracterizada sumariamente como un área cultural que combina el familismo con el estatismo. En la tradición cultural latinoamericana, la familia patriarcal es percibida como el lugar natural de la vida cotidiana. El hogar es la unidad de base de la reproducción; en su interior las relaciones entre sexos y generaciones son jerárquicas, con una clara división del trabajo y de los ámbitos de actividad. Las mujeres están encargadas de las actividades domésticas, las cuales son asociadas con la esfera privada de la reproducción y del mantenimiento de la familia; los hombres tienen a su cargo las tareas asociadas con la esfera pública de la vida social y política. El familismo ha tenido diferentes efectos sobre las posiciones de los hombres y las mujeres. Para estas últimas, esto ha significado subordinación; para los hombres, un esquema de relaciones personales basadas en la solidaridad familiar (entre la parentela), que se extiende a la esfera de la política y de las ac tividades productivas. El esquema masculino de relaciones explica las relaciones de clientelismo y paternalistas, que son tradicionales en la vida pública de Latinoamérica. Tanto para los hombres como para las mujeres, la identidad familiar es la base de la identidad individual y de la construcción de un emplazamiento social. Un fuerte familismo trae consigo una norma que prescribe claramente el matrimonio y el hecho de tener hijos, especialmente para las mujeres (Jelin, 1991, 1992).

México ha recibido una atención considerable de los investigadores interesados en el tema de la familia; la explotación de los registros parroquiales y de los censos en el ámbito de la demografía histórica (sobre todo en lo referente al tamaño de los hogares, su composición y la jefatura femenina de los hogares), ${ }^{3}$ la utiliza-

\footnotetext{
${ }^{3}$ Por lo que se refiere a la investigación más reciente, véase Estudios Demo-
} 
ción de historias de vida para el análisis del papel de las redes de parentesco en el proceso de migración rural-urbana, ${ }^{4}$ el estudio del rol del familismo en la organización de la actividad económica en los sectores medios y altos (Lomnitz y Pérez Lizaur, 1982, 1991), la aplicación de una visión socioeconómica al examen de la relación entre los grupos domésticos y la reproducción cotidiana (de Oliveira y Salles, 1989) o el análisis de la evolución y los determinantes de la participación económica familiar y particularmente femenina (García y de Oliveira, 1990; de Oliveira y García, 1990; Wong y Levine, 1992), son algunos de los trabajos resultado de este interés.

Sin embargo, hay que notar que a pesar del número relativamente elevado de trabajos sobre el hogar y la familia en México, casi todos tienen un alcance local o regional; nuestros conocimientos en el ámbito nacional sobre el tema son aún escasos. Ignoramos, por ejemplo, cuál ha sido la evolución de la composición de los hogares o de las características de los jefes de hogar, o bien, si existen diferencias importantes entre regiones o medios. Existe sólo un puñado de investigaciones, todas ellas recientes, que comienzan a ilustrarlos al respecto. Así, Izazola y López (1990) se interesaron en la composición y la estructura de los hogares así como en el análisis de sus características socioeconómicas. Las autoras trabajaron sobre la base de los censos de 1970 y 1980, sobre todo a partir de los datos de la Encuesta Nacional sobre los Ingresos y Gastos de los Hogares (ENIGH) de 1984. López y González (1989) habían abordado el estudio de la composición de los hogares en los censos mexicanos, pero partiendo de una óptica metodológica. Echarri (1991) presentó la propuesta de una tipología de hogares y su aplicación al análisis de la utilización de servicios de salud infantil, a partir de los datos de la Encuesta Nacional sobre Fecundidad y Salud (Enfes) de 1987. Con base en la misma fuente de datos, Ono (1991) realizó un estudio comparativo con otros países participantes en el programa Encuestas de Salud (EDS) sobre las características de la jefatura femenina de los hogares, e Izazola (1992) propuso una aproximación al estudio de la relación entre el hogar, la familia y la salud. Otros estudios comparativos

gráficos y Urbanos, 1992, vol. 7, núm. 1, consagrado a la demografía histórica mexicana, y el libro Familias novohispanas. Siglos XVI a XIX, coordinado por Pilar Gonzalbo, el cual reúne los trabajos presentados en el seminario sobre historia de la familia del Centro de Estudios Históricos de El Colegio de México.

${ }^{4}$ Se pueden citar los trabajos de Arizpe (1975) sobre las indígenas mazahuas en la ciudad de México, de Lomnitz (1975) sobre una barriada en México y de Balán, Browning y Jelin (1977) sobre la migración en Monterrey. 
de la composición de los hogares habían sido elaborados por De Vos (1987 y 1988), con las encuestas latinoamericanas del programa Encuesta Mexicana de Fecundidad (EMF). Finalmente, Tuirán (1993) desarrolla un análisis comparativo, pero diacrónico, utilizando los datos de las tres principales encuestas demográficas que se han levantado a escala nacional: la EMF de 1977, END de 1976 y la Enfes de 1987.

El cuadro 1 es una síntesis de nuestros conocimientos acerca de la composición de los hogares en México en el ámbito nacional. En él se muestra la evolución de dos características de los hogares mexicanos: la proporción de hogares no nucleares y la proporción de hogares dirigidos por mujeres. Los datos disponibles muestran ciertas tendencias bastante claras: nacionalmente hay un crecimiento, ligero pero sostenido, de la proporción de hogares no nucleares hasta cerca de 1987 , cuando alcanzan cerca de $32 \%$, para descender sensiblemente después hasta niveles de alrededor de un cuarto, según las cifras más recientes. Sin embargo, es posible que el censo de 1970 sobrestime la proporción de hogares nucleares, dada la utilización de un cuestionario por núcleo familiar (Torrado, 1981; López y González, 1989; Tuirán, 1993). Esto relativizaría la disminución de la proporción de hogares nucleares; no obstante, este fenómeno de "nuclearización a la inversa" parece concernir principalmente a las zonas urbanas ${ }^{5}$ y saca a relucir el problema del respeto de los criterios de identificación del jefe del hogar, los cuales son en teoría equivalentes para todas las fuentes. Es posible que durante el trabajo de campo las interpretaciones hayan sido distintas, sobre todo para el caso de la ENIGH; desgraciadamente, nos faltan argumentos con qué responder adecuadamente a estas interrogantes. Este cuadro nos ofrece entonces una imagen de los hogares mexicanos en plena evolución desde la década de los setenta hasta principios de los noventa, y sobre todo, muestra el fenómeno de que la modernización del país se haya visto acompañada, excepto en el pasado más reciente, de un ligero aumento de la proporción de hogares no nucleares, especialmente en las zonas urbanas, más que una nuclearización de los hogares. El otro punto a resaltar es el peso significativo de la jefatura femenina de los hogares: ${ }^{6}$ entre uno de

${ }^{5}$ En vez de zonas urbanas y rurales, la ENIGH diferencia las zonas de alta y de baja densidad, lo cual puede explicar el hecho que en el trabajo citado los autores no encuentren diferencias entre los medios rurales y los urbanos en lo que toca a la proporción de hogares no nucleares.

${ }^{6}$ Este fenómeno no es exclusivo de la época contemporánea: varios trabajos muestran cómo, bajo la dominación española y en el México independiente se han 
cada siete y uno de cada ocho hogares son dirigidos por mujeres, proporción que aumenta ligeramente en las zonas urbanas. Se trata principalmente -en casi $55 \%$ de los casos- de hogares no nucleares, con una proporción elevada de familias monoparentales ${ }^{7}$ (alrededor de 42 por ciento).

CUADRO 1

Estimaciones de la proporción de hogares no nucleares y de hogares -nucleares o no- dirigidos por una mujer en México, según diferentes fuentes

\begin{tabular}{|c|c|c|c|c|c|c|c|c|c|}
\hline $\begin{array}{l}\text { Fuente } \\
\text { y año }\end{array}$ & $\begin{array}{c}\text { Censo } \\
1970 \\
\text { (1) }\end{array}$ & $\begin{array}{c}E M F \\
1976 \\
(2)\end{array}$ & $\begin{array}{c}E N I G H \\
1977 \\
(3)\end{array}$ & $\begin{array}{c}\text { Censo } \\
1980 \\
\text { (1) }\end{array}$ & $\begin{array}{c}E N D \\
1982 \\
(3)\end{array}$ & $\begin{array}{c}E N I G H \\
1984 \\
(1)\end{array}$ & $\begin{array}{c}\text { Enfes } \\
1987 \\
(4)\end{array}$ & $\begin{array}{c}\text { Censo } \\
1990 \\
\text { (5) }\end{array}$ & $\begin{array}{c}\text { Enadid } \\
1992 \\
(6)\end{array}$ \\
\hline \multicolumn{10}{|c|}{ Proporción de hogares no nucleares } \\
\hline Conjunto & 19.3 & 29.0 & 27.6 & 27.2 & 31. & 229. & 531.9 & 25.5 & 26.7 \\
\hline JH hombre & e 17.9 & 20.0 & 23.7 & 23.8 & 28. & 23.9 & 30.2 & 21.2 & 23.6 \\
\hline jH mujer & 27.1 & 40.0 & +51.3 & 46.0 & 55. & 58. & 58.7 & 45.9 & 44.4 \\
\hline $\begin{array}{l}\text { rurales } \\
\text { Zonas }\end{array}$ & 14.7 & - & - & 22.4 & - & 29.5 & 28. & 20.6 & 27.5 \\
\hline urbanas & 22.5 & - & - & 25.1 & - & 29.5 & 33. & 27.3 & - \\
\hline \multicolumn{10}{|c|}{ Proporción de jefes de hogar $(\mathrm{JH})$ mujer } \\
\hline Conjunto & - & 13.6 & 14.1 & 14.0 & 13. & 616.6 & $0 \neq 13$. & 17.3 & 16.5 \\
\hline
\end{tabular}

+24.8 para los jH hombres y 55.8 para las jH mujeres, según (3).

¥15.4, según (3).

Fuente: (1) Izazola y López, 1990; (2) De Vos, 1987; (3) Tuirán, 1993; (4) Echarri, 1991; (5) INEGI, 1993; (6) INEGI, 1994.

El objetivo de este trabajo es presentar un examen de las características de la jefatura de los hogares, un análisis de la composición de los mismos y finalmente, un estudio de las condiciones de vida en ellos. Por otra parte, pretende ser un ejemplo de la utilización de una fuente de información que, a pesar de sus características de disponibilidad y de comparabilidad tanto diacrónica como regional, ha sido subutilizada: las encuestas por muestreo sobre fecundidad. En nuestro caso, utilizaremos los datos de la Enfes,

registrado proporciones elevadas de hogares dirigidos por mujeres (consultar al respecto Estudios Demográficos y Urbanos, 1992, vol. 7, núm. 1; Kuznesof y Oppenheimer (1985) o bien, Arrom (1985).

7 Es decir, hogares constituidos por la jefa e hijos solteros. 
de 1987,8 lo que nos permitirá mostrar el tipo de análisis que es posible realizar con los cuestionarios de hogar de este tipo de encuestas, los cuales rara vez han sido utilizados a pesar de la riqueza de información que contienen.

\section{La jefatura de los hogares}

\section{Significado de la jefatura de los hogares: ¿soporte económico o} autoridad moral?

Existe controversia sobre el término "jefe del hogar" y su significado, al grado de que varios países de Europa utilizan en su lugar la noción de "persona de referencia", al momento de levantar los censos de población. En la Enfes, el jefe del hogar era designado por la persona que respondía al cuestionario de hogar. ${ }^{9}$ En las instrucciones dadas a las encuestadoras, la única condición para que una persona fuese registrada como jefe del hogar era ser reconocida como tal por los demás miembros del hogar. ¿Quién es el jefe del hogar? Puede ser la persona que tiene a su cargo la satisfacción de las necesidades materiales del hogar, el propietario de la vivienda; aquélla a quien se le reconoce una autoridad moral, o bien a quien se le atribuye por su edad avanzada un cierto respeto. Estas diversas posibilidades tendrán repercusiones diferentes en varios ámbitos de la vida del hogar; si se trata de una autoridad moral, la caracterización socioeconómica del hogar no debería formularse en función de los atributos del jefe, sino de los del (o de los) responsable(s) económico(s). Por ejemplo, si nos referimos al tema de la salud, nos interesaríamos en la incidencia

${ }^{8}$ El trabajo de campo de la Enfes fue llevado a cabo por la Dirección General de Planificación Familiar de la Secretaría de Salud, entre febrero y mayo de 1987; en él se visitaron 8130 viviendas, donde se hallaron 8763 hogares, lográndose obtener entrevistas completas en $\mathbf{8 8 . 9 \%}$ de los casos. En los 7786 cuestionarios de hogar completos se encontraron 9709 mujeres en edad fértil (de 15 a 49 años cumplidos); se logró una entrevista completa en $96 \%$ de los casos; 9310 mujeres. El cuestionario de hogar está dividido en dos secciones; en la primera, se indaga sobre las características de los miembros del hogar: relación de parentesco con el jefe, condición de residencia, edad, sexo, condición de actividad económica, ingresos, estado conyugal, nivel de escolaridad, y sobre el jefe del hogar, fecha de inicio de la unión actual. La segunda sección contiene preguntas sobre las características de la vivienda: disponibilidad de agua, electricidad y conexión al drenaje, número de cuartos y dormitorios, material de piso, muros, techo y utilización de la cocina. Para mayor información, véase DGPF (1988a y b) y DGPF-IRD (1989); para una evaluación de la calidad de la información, referirse a Echarri (1989).

9 Sin embargo, no existe forma de saber quién es la persona que respondió al cuestionario de hogar y por lo tanto de conocer sus características. 
de esta autoridad moral sobre el proceso de toma de decisiones, y en particular sobre las decisiones relativas a la identificación de enfermedades, la utilización de servicios de salud y el otorgamiento de cuidados a los enfermos. Es necesario pues, conocer con más detalle las características de las personas designadas como jefas de los hogares al momento del levantamiento de las encuestas y presumiblemente, de los censos. Veamos en un primer término cóınc puede servir a este propósito considerar el ciclo de vida.

\section{El ciclo de vida y la jefatura de los hogares}

Resulta difícil utilizar el concepto de ciclo de vida para el estudio de los hogares, dado que éstos pasan por numerosas transformaciones que no son forzosamente regulares; en cambio, sí es aplicable a los individuos y a los núcleos familiares que los forman, los cuales presentan diferentes etapas que pueden ser predefinidas. La formación de una pareja -o la procreación, en algunos casoses generalmente el primer evento que da origen a un hogar. Las nuevas parejas pueden transformarse en parejas con hijos, en familias monoparentales o bien disolverse; existir como parejas sin hijos, o uniones interrumpidas y sin los hijos solteros corresidentes. Pero en cada una de estas etapas los núcleos familiares pueden adoptar estrategias residenciales diferentes: la independencia o la corresidencia con otro núcleo, ya sea volviéndose núcleo períérico o bien alojando a otros núcleos, conservando la posición de núcleo central y por ende, la dirección del hogar.

El sexo del jefe del hogar es una variable importante en la explicación de la jefatura y la composición de los hogares. En efecto, pueden distinguirse ciertas categorías de hogares dirigidas mayoritariamente por mujeres. ${ }^{10}$ Globalmente, la jefatura de un hogar por una mujer casada o unida es muy rara, puesto que se trata de hogares con núcleo central incompleto: las mujeres jefas de hogar se concentran en las familias monoparentales, los hogares extendidos hacia abajo con núcleo central incompleto y los hogares unipersonales. Algunas jefas de hogar viven solas, pero la mayor parte de ellas vive con sus hijos, solteros o casados, esquema coherente con la idea de una matrifocalidad de la familia mexicana propuesta por ciertos autores como Menéndez (1982).

${ }^{10}$ Haciendo la aclaración que se trata del jefe de hogar declarado en la entrevista, sin tomar en cuenta ningún criterio uniforme, ya sea de orden económico, de edad o de autoridad en el hogar. 
Como se vio en el cuadro 1 , en $86.7 \%$ de los casos la jefatura de los hogares es asumida por un hombre. En cambio, las familias monoparentales son comúnmente dirigidas por mujeres. Más de $60 \%$ de las jefas de hogar tienen más de cincuenta años de edad, mientras que en ese mismo grupo de edad sólo se encuentra $30 \%$ de los jefes hombres. Esto confirma la hipótesis de una relación muy importante entre el ciclo de vida, la composición de los hogares, y su jefatura: si las mujeres se vuelven jefas de hogar después de una disolución de unión, su estructura por edades será forzosamente más vieja. Las edades de los jefes de hogar son bastante coherentes: los hogares nucleares clásicos (con hijos solteros) son dirigidos por jefes jóvenes, mientras que la presencia de otros descendientes implica una edad avanzada del jefe. Sin embargo, el hecho que la mayoría de los jefes de los hogares donde sólo se encuentra la pareja central tengan más de cincuenta años, refuerza la hipótesis según la cual las parejas jóvenes permanecen en el hogar de los padres de uno de ellos. Así, este tipo de hogares (pareja sin hijos) haría referencia más a las parejas con hijos que ya no viven con ellas, que a las parejas más jóvenes, que aún no han tenido hijos.

Hemos señalado ya las diferencias en la estructura por edad de los jefes según el tipo de hogar y el hecho de que los hogares extensos son dirigidos por jefes de mayor edad. La tasa de jefatura de los hogares ${ }^{11}$ (véase la gráfica 1) muestra el efecto del ciclo de vida familiar en relación con los esquemas de corresidencia: antes de los veinte años de edad, la proporción de hombres que dirigen su hogar es muy débil, pero esta proporción aumenta rápidamente hasta la edad de 35 años para permanecer casi constante a partir de esta edad y hasta la vejez. Para las mujeres, el crecimiento de la tasa de jefatura de los hogares es mucho más débil y solamente pasa de $25 \%$ después de los 55 años. En el caso de los hombres, la forma de la curva está ligada a la nupcialidad y específicamente a la formación de uniones conyugales, mientras que la de las mujeres estaría en relación con la disolución de estas mismas uniones. La gran similitud entre las curvas provenientes de la EMF, de la Enfes y del censo de 1990 muestra la estabilidad de los esquemas de jefatura de hogares en México, 12 así como la ausencia de cambios importantes en los esquemas de nupcialidad.

11 Estrictamente hablando, no se trata de una tasa, sino de la proporción de individuos en una categoría dada que son jefes de hogar.

12 Con excepción, quizás, de un ligero aumento en las tasas de jefatura femeninas en el censo de 1990. 
GRÁFICA 1

Tasas de jefatura de los hogares según la edad y el sexo

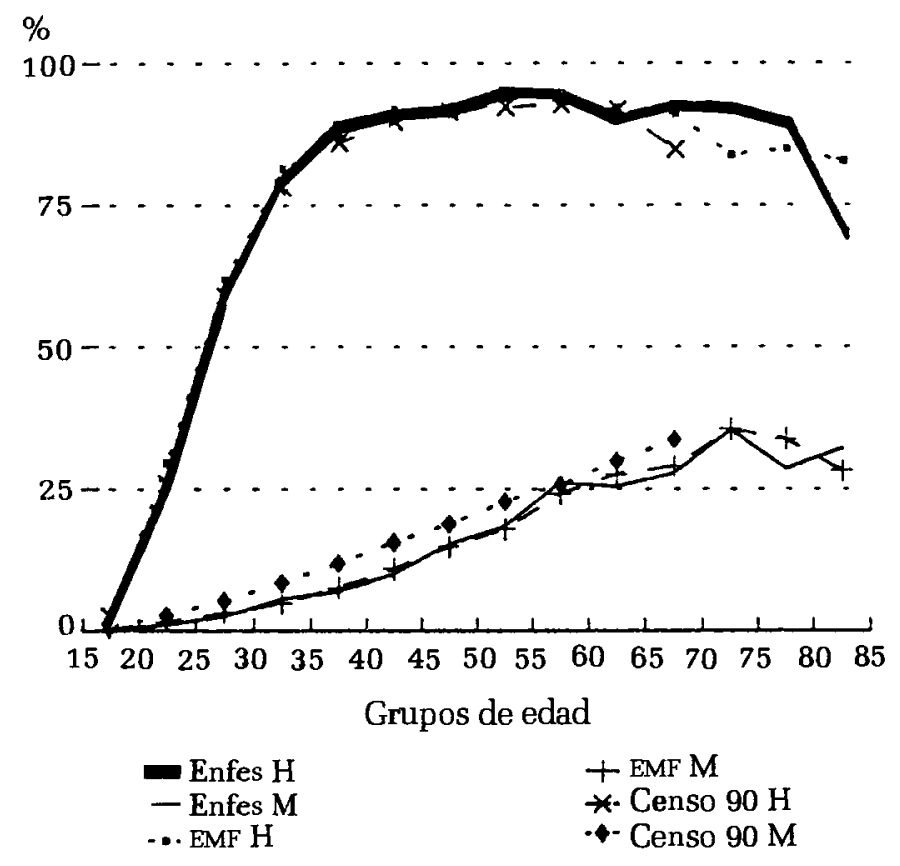

Fuentes: EMF, 1976; Enfes, 1987; censo 1990.

Sin embargo, debemos considerar también la situación conyugal de la población en el análisis de las tasas de jefatura de los hogares (véase la gráfica 2). Para los hombres unidos (casados o en unión libre), la progresión de la proporción de jefes de hogar es un índice de la propensión de las parejas jóvenes a permanecer en el hogar parental formando así un hogar extenso, lo cual correspondería a una regla de residencia virilocal o uxorilocal, en oposición a un esquema neolocal,13 bajo el cual las uniones implican

$13 \mathrm{Si}$ las costumbres en una sociedad indican que una pareja recién formada establezca su residencia en casa de los padres del novio, se habla de una regla de residencia virilocal o patrilocal; si pasan a vivir a casa de los padres de la novia, la regla se llama uxorilocal o matrilocal; cuando no hay una preferencia y la pareja puede residir en casa de los padres de cualquiera de los dos, se trata de una regla de residencia bilocal; si la pareja de recién casados establece un domicilio independiente de la vivienda de los padres de ambos, se dice que es una residencia 
una independencia residencial. Puede observarse que en México existe una proporción importante de hombres unidos que cuando son jóvenes viven en un hogar del cual no son los jefes, es decir, la generación de los padres toma a su cargo los núcleos familiares jóvenes. Esta proporción disminuye muy rápido, pasando de $45 \%$ a los veinte años, a $28 \%$ a los veinticinco y a $10 \%$ a los treinta años. Después de los 35 años de edad casi todos los hombres unidos dirigen sus hogares. Encontramos aquí indicios de una neolocalidad atenuada o diferida en espera de poder asumir los costos de la independencia residencial. Inversamente, las mujeres se convierten en jefas de hogar después de la disolución de una unión y por ende después de una cierta edad; esta relación entre el ciclo de vida de los individuos, los núcleos familiares y la composición de los hogares se hace más clara cuando se consideran las tasas de jefatura por estado civil y sexo.

GRÁFICA 2

Tasas de jefatura de hogares según el sexo, la edad y la condición de unión

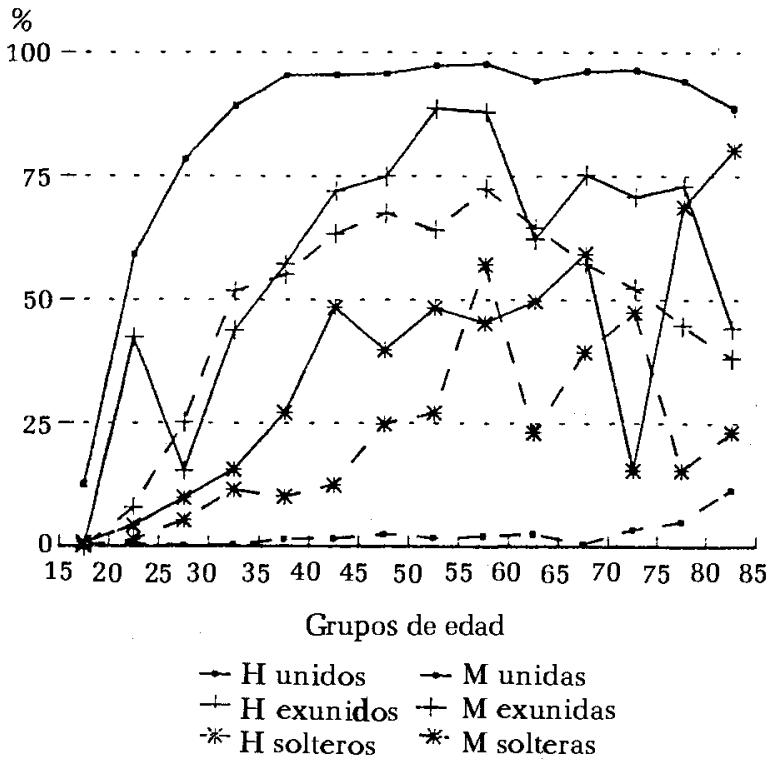

Fuente: Enfes, 1987.

neolocal; finalmente, en algunas sociedades se usa que las nuevas parejas se muden con un tío materno del novio, lo que se conoce como avumcolocalidad (Murdock, 1949: 16). 
La jefatura femenina de un hogar es asunto, sobre todo, de mujeres no unidas y particularmente de mujeres antiguamente unidas; después de los treinta años de edad una de cada dos mujeres en estas condiciones dirige su hogar. Sin embargo, después de los 55 años la tendencia se invierte y las mujeres de más edad dirigen cada vez menos sus hogares. Los hombres ex-unidos (viudos, divorciados o separados) adoptan el mismo comportamiento: permanecen en el hogar de los padres si son jóvenes, y dirigen su propio hogar una vez que han pasado la treintena. Entre los solteros la tendencia a dirigir su hogar es un poco más fuerte para los hombres, pero el cálculo de estas proporciones se ve afectado por el pequeño número de casos dado que el celibato definitivo es un fenómeno raro en México (Quilodrán, 1985, 1991).

Esto nos lleva a una reflexión sobre los esquemas de residencia de los mexicanos y las mexicanas. Basándonos en las tasas de jefatura presentadas, podemos emitir la hipótesis de que la trayectoria más frecuente sería la de un matrimonio o unión relativamente precoz; ${ }^{14}$ el o la mexicana permanece en casa de los padres durante algunos años y más tarde, seguido de la llegada de los hijos, la pareja se independiza. El hombre asume entonces la jefatura del nuevo hogar hasta su muerte y entonces su viuda lo reemplaza.

Para verificar esta hipótesis, nos harían falta historias de unión que incluyesen esquemas de corresidencia. Podría verificarse entonces si las parejas jóvenes permanecen con los padres y cuáles son los factores que generarán su autonomía: la disponibilidad de una vivienda (ya sea por construcción, compra o alquiler), la presencia de hijos, el alcanzar una cierta edad o bien la presencia de varios núcleos familiares en una misma vivienda.

\section{Un modelo de determinantes de la jefatura de los hogares}

Después de haber considerado las características de los jefes de hogar de manera independiente, nos ocuparemos ahora del análisis de sus efectos cuando se consideran todas las variables de manera conjunta. Para esto, propondremos una regresión logística de la probabilidad de dirigir un hogar aplicada a los residentes habituales de los hogares, de 15 años y más, considerando de manera separada a hombres y mujeres.

\footnotetext{
14 De las mujeres entre 20 y 44 años de edad, $44 \%$ habían contraído una unión antes de los 20 años. Esta proporción es superior a $53 \%$ para el grupo de edad 30-34 y a $65 \%$ entre las mujeres de 20 a 49 años en el medio rural.
} 
Por medio de los modelos logísticos, los momios 15 de dirigir un hogar (es decir, de ser identificado como el jefe del hogar) pueden ser estimados para las diferentes modalidades de cada variable independiente categórica, controlando el efecto de las demás variables (Halli y Shiva, 1992). Para una variable dependiente dicotómica dada, los momios se definen como la relación entre las probabilidades de éxito (positivas) respecto de las probabilidades de fracaso (negativas). Generalmente, los momios se expresan como razones, tales como $p /(1-p)$, y los valores de los parámetros son calculados utilizando el método de máxima verosimilitud. Si queremos estimar la existencia de la jefatura de un hogar por parte de un individuo en función de $\mathrm{n}$ variables independientes $\mathrm{X}_{1} \ldots$ $\mathrm{X}_{\mathrm{n}}$, la probabilidad de ser el jefe del hogar podría ser expresada como:

$$
\operatorname{Prob}(\text { jefatur } a)=\frac{e^{\beta_{\mathrm{o}}+\beta_{1} X_{1}+\beta_{2} X_{2}+\ldots+\beta_{\mathrm{n}} X_{\mathrm{n}}}}{1+\mathrm{e}^{\beta_{\mathrm{o}}+\beta_{1} X_{1}+\beta_{2} X_{2}+\ldots+\beta_{\mathrm{n}} X_{\mathrm{n}}}}
$$

o de forma equivalente:

$$
\operatorname{Prob}\left(\text { no jefatura) }=\frac{1}{1+e^{\beta_{o}+\beta_{1} X_{1}+\beta_{2} X_{2}+\ldots+\beta_{n} X_{n}}}\right.
$$

y los momios de jefatura como:

$$
\frac{\operatorname{Prob}(\text { jefatura })}{\operatorname{Prob}(\text { no jefatura })}=e^{\beta_{o}+\beta_{1} X_{1}+\beta_{2} X_{2}+\beta_{\mathrm{n}} X_{\mathrm{n}}}
$$

El modelo logístico es formulado como el logito de las probabilidades de jefatura, o en otros términos, en una ecuación logística el logaritmo natural de los momios de la variable dependiente es una función lineal de las variables independientes, de la manera siguiente:

15 Aun si el término correcto para la variable dependiente es el de momios (odds en inglés), para facilitar la lectura utilizaremos en adelante indistintamente "riesgos relativos" o probabilidades, para designarlos en su sentido intuitivo. El valor de la probabilidad de ocurrencia de un evento, stricto sensu, está dado por la ecuación (1) o la ecuación (2). 


$$
\log (\text { momios de jefatura })=\beta_{\mathrm{o}}+\beta_{1} X_{1}+\beta_{2} X_{2}+\ldots+\beta_{\mathrm{k}} X_{\mathrm{k}}
$$

donde $\beta_{1}$ represente el efecto de la primera variable independiente, sobre el logito de la jefatura del hogar (o bien el logaritmo de los momios de la jefatura del hogar), controlando los efectos de las variables 2 a $n$.

Se utilizó el paquete SPSS/PC+ (Norusis, 1986 y 1990), para ajustar dos modelos logísticos (uno para cada sexo) a los datos de la Enfes. En el caso de variables independientes con $n$ categorías, el procedimiento Logistic Regression utiliza una representación de efectos de códigos (effect-coding representation) y las transforma en n-1 variables ficticias dicotómicas para cada categoría de la variable de interés. El esquema de codificación utilizado de oficio es el de desviación (deviation), en el que los coeficientes estimados pueden ser interpretados como las desviaciones del efecto global, es decir, de un promedio entre las categorías. Este promedio es la media geométrica de los efectos de las categorías de una variable y es tomado como punto de referencia en la ecuación logística, la cual está en una escala logarítmica. El coeficiente de la categoría de referencia (generalmente la última) es la suma, con un signo negativo, de los coeficientes de las demás categorías. Otra opción, que hemos privilegiado, es la utilización de contrastes simples; en este caso, los coeficientes representan el efecto de cada categoría comparándolo con el de una categoría de referencia cuyo coeficiente es necesariamente igual a cero, puesto que no difiere de ella misma. La interpretación de los coeficientes para las dos opciones es la misma ya que sólo están desplazados: centrados sobre el cero, en el caso de las desviaciones, o sobre el valor de la categoría de referencia, en el caso de los contrastes simples.

La ecuación logística podría entonces escribirse como:

(Momios de jefatura)

$$
L o g=\beta_{o}+\sum_{i} \beta_{i 1} X_{i 1}+\sum_{j} \beta_{j 2} X_{j 2}+\ldots+\sum_{k} \beta_{k n} X_{\mathrm{kn}}
$$

donde $\mathrm{X}_{\mathrm{i} 1}$ es la i-ésima categoría de la primera variable, $\mathrm{x}_{\mathrm{i} 2}$ es la j-ésima categoría de la segunda variable, $\mathrm{y}_{\mathrm{kn}}$ es la k-ésima categoría de la enésima variable. Si consideramos la exponenciación de la ecuación es evidente que los parámetros tienen un efecto multiplicativo. Pueden ser interpretados como los momios relati- 
vos a la media geométrica de los efectos de las categorías de una variable. 16

Para establecer un modelo de determinantes de la jefatura de los hogares, consideramos cinco variables nominales independientes, tanto para los hombres como para las mujeres: la edad, el nivel de instrucción, la condición de unión, la actividad y el medio de residencia. Las categorías de referencia son, respectivamente, el grupo de edad de 50 a 59 años, la primaria incompleta, los unidos(as), los inactivos(as) y las zonas urbanas, con el esquema de contraste simple. Los dos modelos logísticos tuvieron un muy buen ajuste a los datos de la Enfes: además de los niveles de significación estadística de las dos ecuaciones $\left(-2 L L, \chi^{2}\right.$ y bondad de ajuste) cuyos coeficientes se presentan en el cuadro 2 , el modelo predice correctamente $89 \%$ de los casos para los hombres y $94 \%$ para las mujeres.

${ }^{16}$ Si se dispone de un tamaño de muestra suficientemente grande, se puede ргоbar si un coeficiente es igual a сего рог medio de la estadística Wald, la cual se define como el cuadrado del coeficiente dividido por su desviación estándar. Esta estadística tiene una distribución $X^{2}$, y en el caso de variables nominales, el número de grados de libertad es igual al número total de categorías menos uno. En la regresión logística, así como en la regresión lineal múltiple, es difícil determinar la contribución individual de cada variable, pues éstas dependen de las otras variables del modelo, lo que provoca problemas cuando las variables consideradas como independientes están fuertemente correlacionadas. Una medida de la correlación parcial entre la variable dependiente y cada una de las variables independientes es la estadística $R$. Ésta puede variar de menos uno a uno, y los valores positivos indican que la probabilidad de ocurrencia del evento aumentan con el valor de la variable. Valores de $R$ cercano a cero indican una débil contribución parcial de la variable al modelo. Su fórmula es:

$$
\mathrm{R}=\sqrt{\frac{\text { Estadística Wald }-2 g l}{-2 \text { Log Verosimilitud (0) }}}
$$

Una forma de determinar la medida en que el modelo se ajusta a los datos es comparar las estimaciones con los resultados observados. Puede disponerse del porcentaje de casos correctamente estimados, de falsos positivos, así como de falsos negativos. Otro procedimiento que nos permite validar el modelo logístico es considerar la verosimilitud (likelihood) de los resultados de la muestra, dados los parámetros estimados, es decir, la probabilidad de encontrar los resultados obtenidos dados tales parámetros. La medida del ajuste del modelo a los datos es igual a menos dos veces el logaritmo de la verosimilitud $(-2 \log$ Likelihood o $-2 L L)$. Mientras más cercana sea la verosimilitud a uno, el modelo será mejor. Bajo la hipótesis nula de que el modelo se ajusta perfectamente, $-2 L L$ tiene una distribución $\chi^{2}$ con $N$-p grados de libertad, donde $N$ es el número de casos y $p$ el número de parámetros estimados.

Otra estadística, llamada bondad de ajuste (en inglés goodness-of-fit), compara las probabilidades observadas con las previstas por el modelo. Se define como:

$$
Z^{2}=\sum_{i} \frac{\left(Y_{i}-P_{i}\right)^{2}}{P_{i}\left(1-P_{j}\right)}
$$

donde $Y_{i}$ es el valor observado. Esta estadística tiene también una distribu- 
CUADRO 2

Coeficientes de regresión logística sobre los determinantes de la jefatura de los hogares, según el sexo

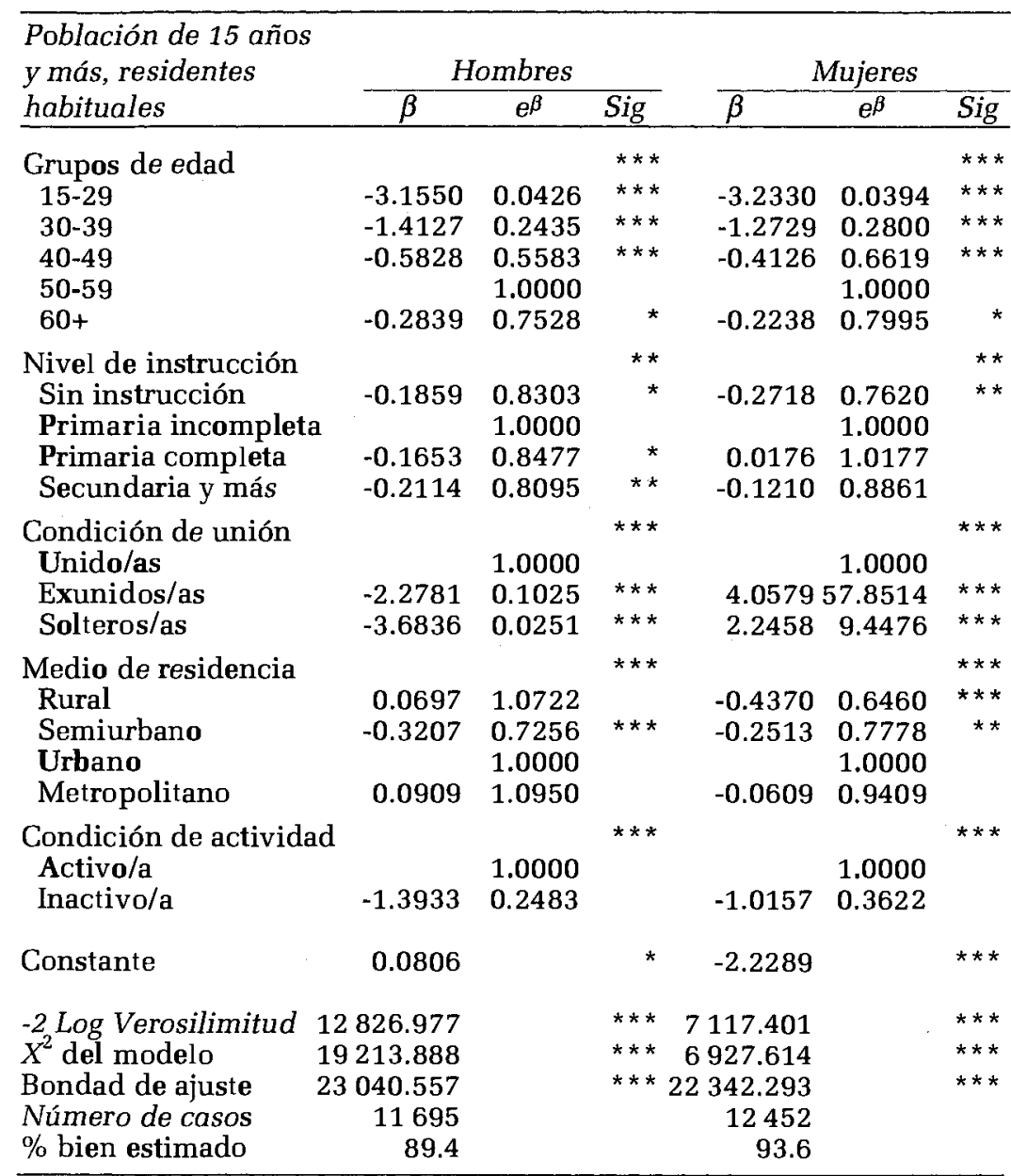

Las categorías de referencia se indican en negritas.

Nivel de significación: * $p<0.05 ;{ }^{* *} p<0.01 ; * * * 0<0.001$.

Fuente: Enfes, 1987.

ción $\chi^{2}$, si el modelo ajustado es el correcto, con $N-p$ grados de libertad. La última de las medidas de ajuste es la estadística $\chi^{2}$ del modelo, que es la diferencia de las estadísticas $-2 L L$ entre un modelo con solamente una constante y el modelo considerado. Esta estadística prueba la hipótesis nula de que los coeficientes de todos los términos del modelo, excepto la constante, son nulos. Es comparable a la estadística $F$ utilizada en las regresiones lineales. 
La interpretación de los coeficientes es la siguiente: tanto en el caso de los hombres como en el de las mujeres, las cinco variables consideradas tienen una relación significativa, en términos estadísticos, con las probabilidades de dirigir un hogar; la estadística $R$ presenta los valores más elevados en las variables condición de unión (0.3646 y 0.3834) y el grupo de edad (0.2495 y 0.2231). La condición de unión es pues la variable que explica en mayor medida el hecho de dirigir un hogar, pero la dirección de su efecto para los hombres es opuesta a la de las mujeres (véase la gráfica 3 ).

GRÁFICA 3

Efectos de diferentes variables sobre los momios de la jefatura de los hogares

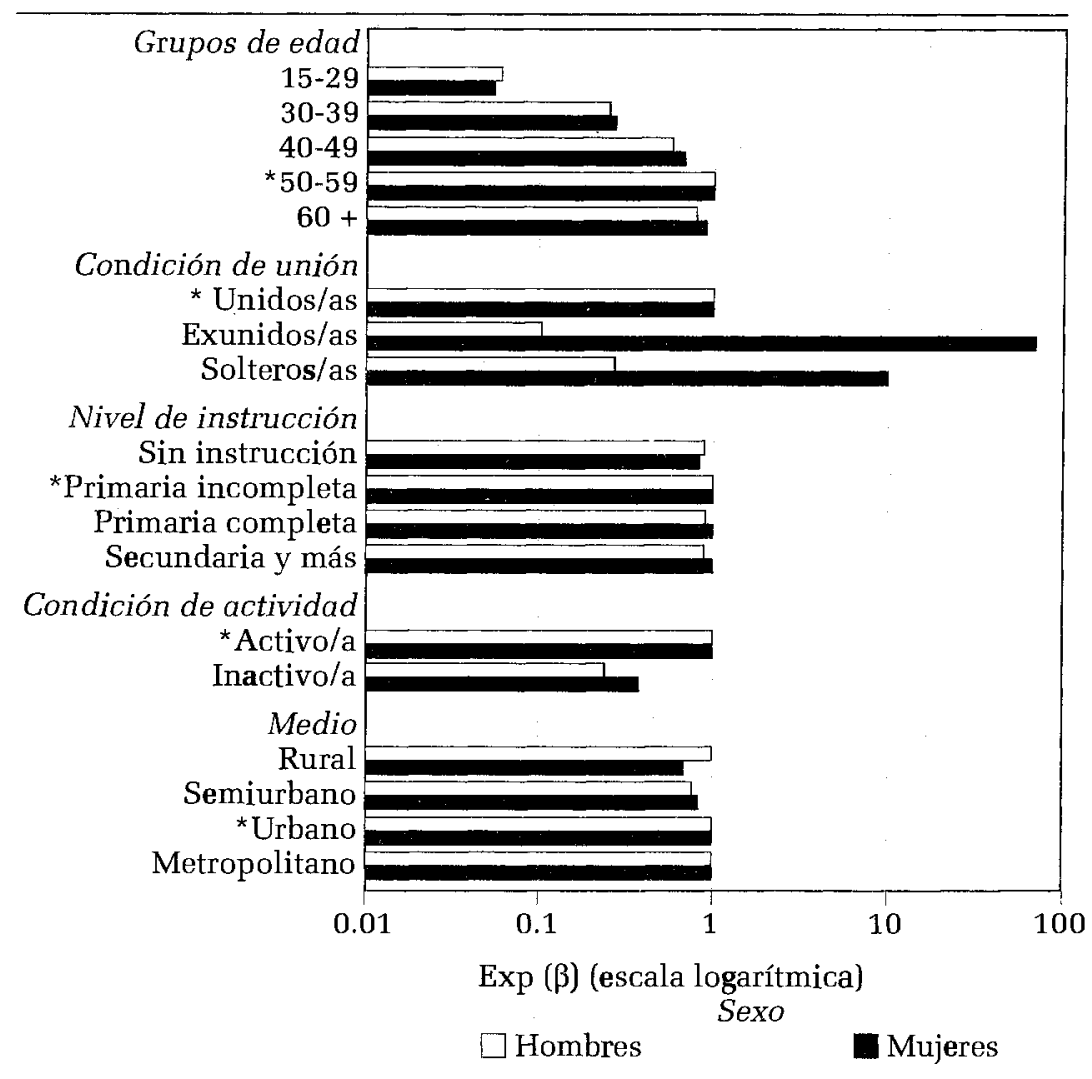

* Categoría de referencia. Nivel de significación: 0.05 .

Fuente: Enfes, 1987. 
En contraste, los efectos de la variable "grupo de edad" van en la misma dirección para los dos sexos: los momios son muy reducidos para las personas menores de 30 años (alrededor de $4 \%$ ) y las probabilidades de ser el jefe del hogar para el grupo 30-39 sólo representan una cuarta parte (24\% para los hombres y $28 \%$ para las mujeres) de las del grupo de referencia 50-59. Este grupo de edad representa la etapa de formación de las familias para los hogares nucleares dirigidos por hombres y de los hogares extendidos horizontalmente dirigidos por mujeres. Cuando se consideran los grupos de edad más avanzada, hay un crecimiento de los riesgos relativos (después de los 40 años representan $56 \%$ de los momios de referencia para los hombres y $66 \%$ para las mujeres), la cúspide se alcanza en la categoría de referencia (50-59) y después de los 60 años se observa una reducción, a $75 \%$ en los hombres y $80 \%$ en las mujeres. ${ }^{17}$ Estos coeficientes muestran de manera muy clara el impacto del ciclo de vida sobre la jefatura de los hogares. La tendencia a convertirse en jefe del hogar no es una característica de los individuos jóvenes. Aun si la formación de nuevas familias tiene lugar generalmente antes de los cuarenta años, la independencia de estas familias, entendida como la constitución de nuevos hogares, parece ser más frecuente alrededor de los 50 años, tanto para los hombres como para las mujeres. Esto podría también estar asociado con la transmisión de la posición de jefe del hogar, en los hogares donde el jefe anterior fallece o bien, a la disolución del núcleo central en el caso de la jefatura femenina; también es posible que el jefe del hogar deje de ser considerado como tal, por razones de salud, de incapacidad o de inactividad y que la jefatura del hogar se transferida a uno de sus hijos. Observemos con más detalle cada una de las variables consideradas.

\section{Nivel de instrucción}

La instrucción ocupa también un lugar importante, aunque mucho menos significativo, en la determinación de la jefatura de los hogares. Sus efectos son diferentes según el sexo: para las mujeres, sólo la categoría "sin instrucción" tiene una relación significativa (al umbral de 10\%) y de signo negativo. Por lo que toca a

\footnotetext{
17 Hay que tomar en cuenta que el peso relativo de los grupos de edad más avanzada es muy reducido, dado los niveles de esperanza de vida en México, los cuales estaban estimados para 1980 en 63.2 años para los hombres y en 69.4 para las mujeres (Camposortega, 1988).
} 
los hombres, todas las categorías presentan riesgos relativos del orden de $20 \%$ en relación con la categoría de referencia, "primaria incompleta".

La escolaridad de los jefes de hogar refleja las mejoras recientes en el nivel de instrucción de la población mexicana, así como las desigualdades entre los sexos -los jefes hombres tienen niveles de instrucción más elevados que las jefas-y entre los diferentes medios de residencia: la proporción de jefes de hogar instruidos aumenta con la oferta de servicios educativos, más abundante en las localidades urbanas.

Resulta importante comparar la instrucción de los jefes de hogar con la de los demás miembros de los hogares, tomando en consideración las diferencias en la estructura por edades. Entre las mujeres, al momento de controlar el efecto de la edad, resulta que las jefas de hogar son un poco más instruidas que las no jefas, cualquiera que sea su edad. Entre los hombres, esto sólo se observa para los jefes de más de 40 años de edad (véase la gráfica 4). Podría pensarse entonces que a las mujeres que tienen un nivel de instrucción más elevado les resulta más fácil acceder al mercado de trabajo o a niveles de remuneración más elevados, que les permiten satisfacer las necesidades de su hogar, pero el pequeño número de efectivos nos impide trascender el estadio de la especulación. Los hombres que tienen características desfavorables frente al mercado de trabajo encontrarán dificultades para satisfacer las necesidades de su propio hogar, lo cual a su vez podría dificultar la dirección del mismo.

El nivel de escolaridad de los cónyuges sirve de indicador de la homogamia, es decir, de la tendencia de las personas a unirse con individuos con los que se comparten ciertas características socioeconómicas. Los jefes de hogar hombres sin escolaridad están en su mayor parte casados con mujeres que no completaron su instrucción primaria; la proporción de esposas sin instrucción disminuye fuertemente con el aumento del nivel de escolaridad del marido, al mismo tiempo que la proporción de cónyuges con secundaria y más aumenta con la instrucción del jefe. Para las jefas de hogar unidas, la tendencia es menos clara (la proporción de jefas de hogar con el mismo nivel de instrucción que su cónyuge es $47.2 \%$, contra $55.8 \%$ entre los jefes hombres), debido sobre todo al reducido número de casos, pero también a un exceso de casos de esposos que han seguido por lo menos estudios de secundaria, lo que confirma el carácter muy particular de esta categoría de jefas de hogar. 
GRÁFICA 4

Número promedio de años de escolaridad según el sexo, la edad y la condición de jefatura del hogar

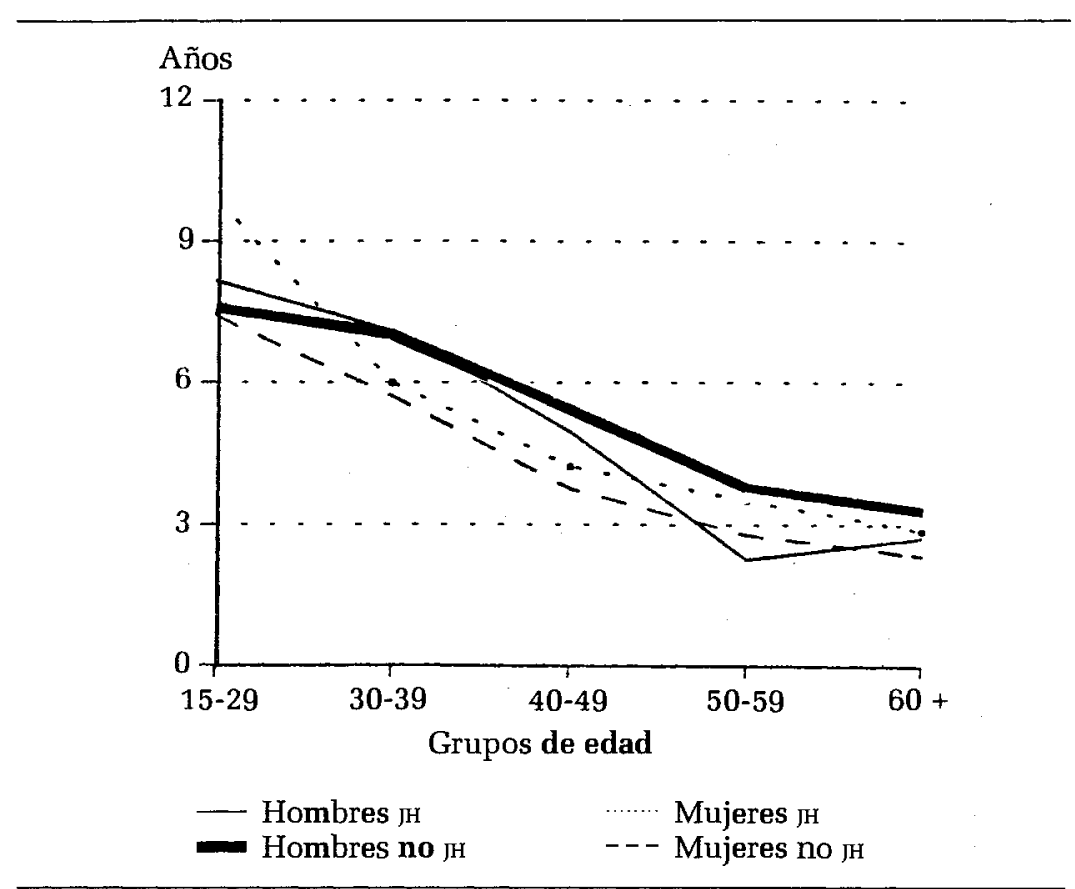

Fuente: Enfes, 1987.

\section{Condición de unión}

Tal y como habíamos visto, la condición de unión es la variable con mayor capacidad explicativa de la jefatura de los hogares. En el caso de los hombres, la categoría "unidos" está fuertemente asociada con la posición de jefe del hogar; los hombres casados o unidos dirigen sus hogares más frecuentemente que el resto: el hecho de tener una unión interrumpida (por viudez, separación o divorcio) reduce sus probabilidades de ser el jefe del hogar a $10 \%$ y los momios de los solteros son solamente de uno sobre cuarenta, siempre en relación con los casados. Los efectos se invierten entre las mujeres: las probabilidades de las solteras se multiplican por 9 y aquéllas con uniones interrumpidas presentan riesgos relativos de casi 60 veces las de las casadas o unidas. 
El estado civil en combinación con el sexo, caracteriza la condición de jefe del hogar. La gráfica 5 muestra cómo para los hombres la jefatura del hogar está estrechamente ligada a la condición de unión: $\mathbf{8 1} \%$ de los jefes son casados y $\mathbf{1 1 \%}$ unidos, mientras que los no unidos son mayoritariamente solteros. Las jefas de hogar son sobre todo viudas ( $55 \%$ ), separadas o divorciadas $(37 \%)$, y solamente una de cada ocho es soltera. Las mujeres no jefas de hogares se dividen en casadas y solteras. Puede decirse entonces que si un hombre contrae una unión, tendrá mayores posibilidades de convertirse en jefe de hogar que si permanece soltero.

\section{GRÁFICA 5}

Distribución del estado civil según el sexo y la condición de jefatura del hogar

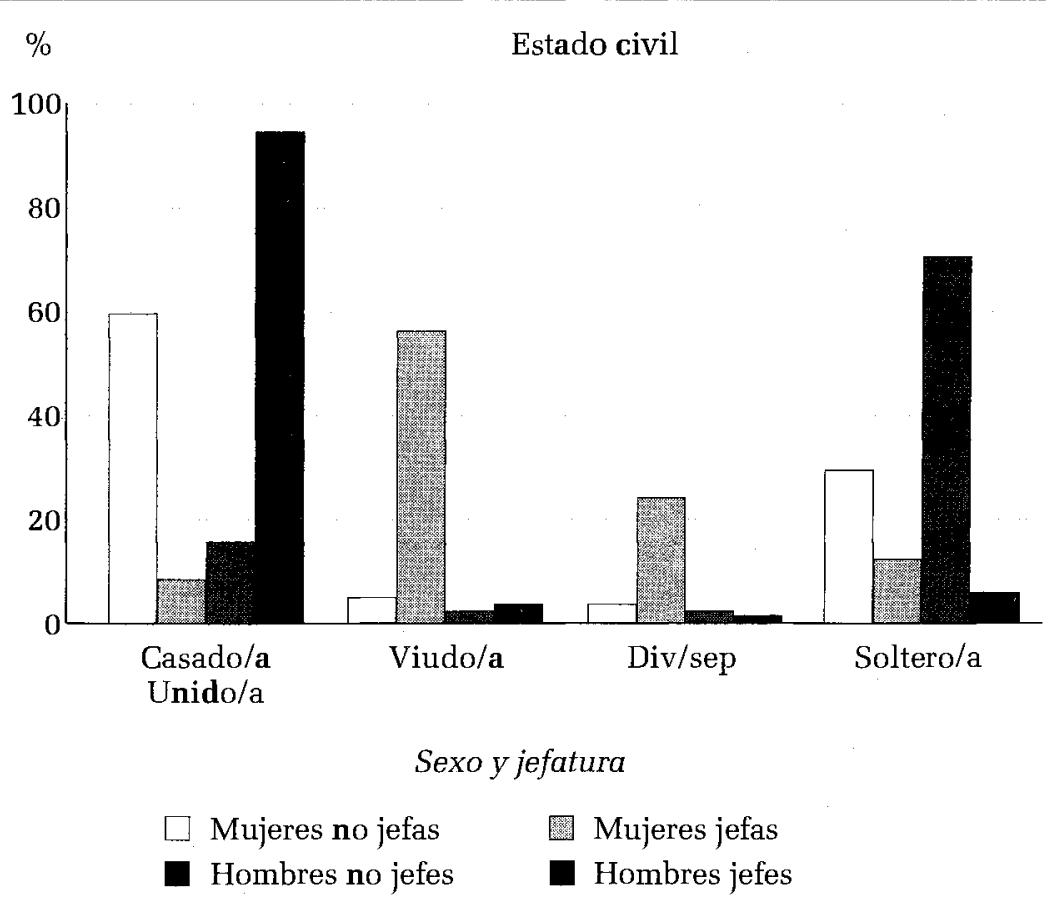

Fuente: Enfes, 1987; población de 15 años y más. 


\section{El medio de residencia}

La relación entre el medio de residencia y las probabilidades de jefatura es estadísticamente significativa para los dos sexos. El sentido de la relación, sin embargo, difiere entre hombres y mujeres. Para los primeros, tiene forma de ' $U$ ', encontrándose los riesgos relativos más bajos en las zonas semi-urbanas (73\%); el hecho de vivir en una zona rural o en una metropolitana trae consigo probabilidades de jefatura superiores en alrededor de $8 \%$ respecto de las zonas urbanas. En lo concerniente a las mujeres, los signos correspondientes a las categorías significativas también son diferentes: los riesgos relativos de los medios rurales se reducen $35 \%$, mientras que las probabilidades de jefatura de mujeres que viven en zonas metropolitanas no difieren significativamente respecto de las que residen en medios urbanos.

Contradiciendo las tesis de Goode y el paradigma de Parsons sobre la nuclearización de los hogares debida a los efectos de la modernización, resulta que es en las zonas rurales donde se encuentra la proporción más alta de hogares nucleares. Esto puede ser resultado de factores tales como el mayor espacio disponible, que facilita la independencia de los nuevos núcleos familiares, pero también de la migración hacia las ciudades, en donde la parentela funciona como una red de acogida y de sostén para los recién llegados (Jelin y Paz, 1992). Esto explicaría por qué la proporción de hogares con extensión horizontal es dos veces mayor en las zonas metropolitanas que en los medios rurales (Echarri, 1991).

Pueden entonces distinguirse varios esquemas de corresidencia en función del medio. Los hogares unipersonales son más bien urbanos: podemos pensar que la inexistencia -o la casi inexistencia-18 de pensiones de jubilación o bien su escaso monto, son argumentos suficientemente importantes como para disuadir a los ancianos en los medios rurales de vivir solos. La existencia en las ciudades de redes de solidaridad, reforzadas por la proximidad de la familia y de los vecinos, originan estas diferencias. La proporción de familias monoparentales crece con el tamaño de la localidad y las oportunidades de trabajo que allí existen. Para una mujer con una unión interrumpida y con hijos a su cargo, la solución parece ser la corresidencia con sus padres, sobre todo en los me-

18 Ham (1993) estima en $47 \%$ la proporción de la población económicamente activa que no está cubierta por un plan de pensiones de retiro. Por otra parte, para $92 \%$ de los pensionados del imss, el monto de la pensión era de alrededor de $\$ 300,000$ mensuales y lo que es aún más grave, $82 \%$ de las personas de más de 60 años de edad no disponen de una pensión de jubilación. 
dios semiurbanos, donde uno de cada cinco hogares es extendido hacia abajo.

\section{La actividad de los jefes de hogar}

La condición de actividad fue incluida en el modelo con el fin de probar la hipótesis del carácter económico de la jefatura de los hogares. Sin embargo, es necesario precisar que nuestra fuente de datos no ofrece información sobre fuentes de ingreso diferentes al salario. En consecuencia, sólo podemos suponer que si la jefatura de los hogares reviste un carácter esencialmente económico, las personas que ejercen actividades remuneradas representarían entonces una mayor proporción de jefes de hogar que los inactivos. En efecto, puede constatarse que el hecho de tener un trabajo está ligado de manera positiva y relativamente fuerte a la jefatura de los hogares: los riesgos relativos de los inactivos son de $\mathbf{0 . 2 5}$ para los hombres y de $\mathbf{0 . 3 6}$ para las mujeres, respecto de los activos. La gráfica 6 muestra las tasas de actividad según el sexo y la edad, para los jefes y demás miembros de los hogares. Resulta claro que para los jefes hombres la actividad económica es más intensa que para los no jefes, y que las mujeres que dirigen su hogar se ven obligadas a trabajar. En los hogares dirigidos por un hombre, casi todos los jefes tienen un trabajo remunerado, mientras que en el caso de la jefatura femenina, aun si las tasas de actividad son muy elevadas, descienden más rápido que en el caso de los hombres; si consideramos la estructura por edad de las jefas de hogar, encontramos que en promedio más de una jefa de cada tres no trabaja y se dedica a las tareas domésticas.

\section{Los niveles de ingresos}

La información sobre ingresos proporcionada por las encuestas de fecundidad como la Enfes debe ser utilizada con prudencia: este tipo de instrumentos no fue diseñado con el fin de conocer exactamente los niveles de los salarios y de otros ingresos; sin embargo, pueden ayudarnos a resaltar las desigualdades entre diversos subconjuntos de la población. Hay que señalar también que la encuesta mide los ingresos percibidos el mes anterior a la fecha de la entrevista ${ }^{19}$ y que sus niveles pueden verse afectados por variaciones estacionales o coyunturales.

19 En el cuestionario de hogar se preguntaba para cada persona de 8 años y más si había ejercido una actividad por la cual hubiera recibido dinero o remune- 


\section{GRÁFICA 6}

Tasas de actividad por grupos de edad, sexo y condición de jefatura de los hogares

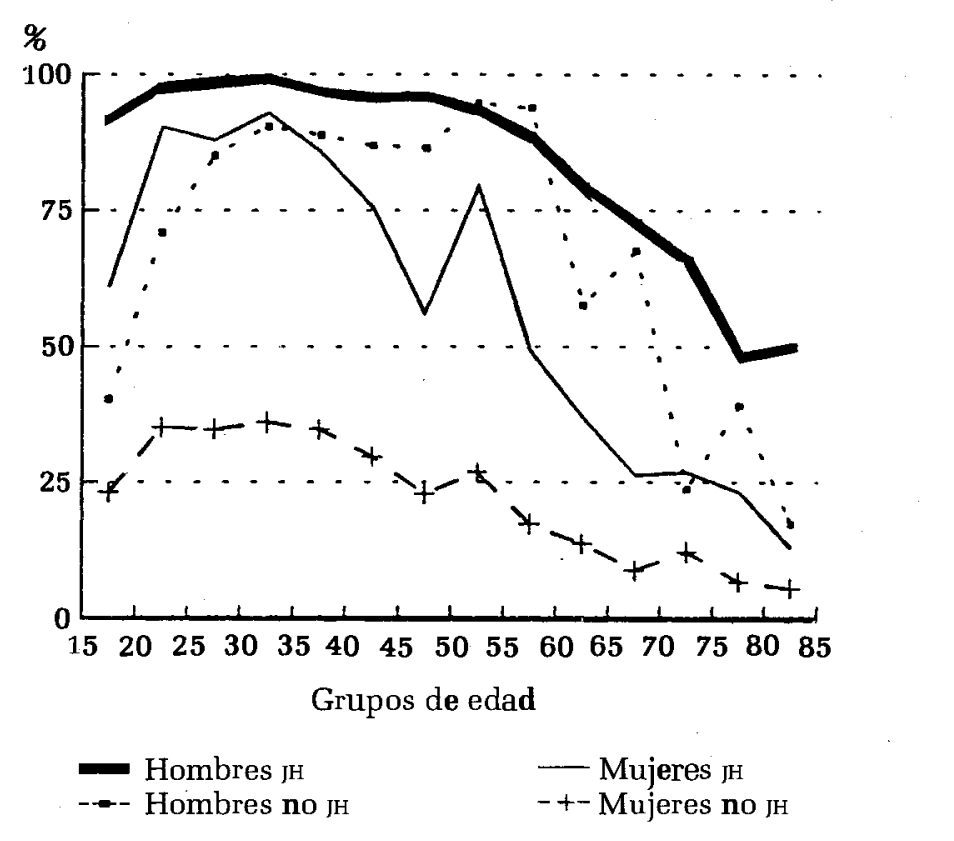

Fuente: Enfes, 1987.

Una primera desigualdad aparece en la gráfica 7, la cual presenta la distribución de los ingresos de los jefes y no jefes de hogar, según el sexo. Es claro que los salarios de las jefas de hogar son inferiores a los de los hombres, pero solamente un poco más de la mitad de las jefas de hogar tiene una actividad remunerada. Para considerar los niveles de ingresos de un hogar y en consecuencia sus condiciones económicas, es necesario tomar en cuenta en el análisis los ingresos del conjunto de miembros del hogar. Calculamos así los ingresos promedio en relación con el salario

ración en especie. Si se recibía una respuesta afirmativa, se pedía que se clasificaran los ingresos totales del mes anterior entre diez grupos, en relación con el salario mínimo (sm) vigente en la zona a la fecha de la entrevista: menos de 1/4 sm, de 1/4 a $1 / 2 \mathrm{sm}$, de $1 / 2$ a $1 \mathrm{sm}, 1 \mathrm{sm}$, de 1 a $2 \mathrm{sm}$, de 2 a $3 \mathrm{sm}$, de 3 a $5 \mathrm{sm}$, de 5 a $10 \mathrm{sm}$, más de $10 \mathrm{sm}$ y sin ingresos el mes precedente. Para el cálculo de promedios y distribuciones se consideró el punto medio del rango. El nivel de no respuesta para esta pregunta fue de $\mathbf{5 . 9}$ por ciento. 
mínimo legal de los jefes y no jefes de hogar, según el medio de residencia, la edad y el sexo (cuadro 3). Cuando los jefes de hogar ejercen una actividad económica, en general son mejor remunerados que los demás miembros del hogar y su contribución económica es la más importante. Sin embargo, la relación de causa-efecto puede ser inversa, es decir, en vez de que dirijan sus hogares porque su salario es el más importante, que perciban salarios más elevados porque dirigen un hogar, siendo entonces su papel como sostén económico un factor en la determinación de sus salarios. 20

\section{CUADRO 3}

Ingresos promedio de los jefes y de otros miembros de los hogares respecto del salario mínimo legal, según el medio, la edad y el nivel de instrucción

\begin{tabular}{|c|c|c|c|c|}
\hline & \multicolumn{2}{|c|}{ Hombres } & \multicolumn{2}{|c|}{ Mujeres } \\
\hline & No jefes & Jefes & No jefes & Jefes \\
\hline \multicolumn{5}{|l|}{ Medio de residencia } \\
\hline Rural & 0.57 & 0.55 & 0.43 & 0.36 \\
\hline Semiurbano & 0.82 & 1.08 & 0.73 & 0.74 \\
\hline Urbano & 1.28 & 1.78 & 1.22 & 0.95 \\
\hline Metropolitano & 1.17 & 1.60 & 1.08 & 1.10 \\
\hline \multicolumn{5}{|l|}{ Grupos de edad } \\
\hline $15-29$ & 0.95 & 1.20 & 0.91 & 1.44 \\
\hline $30-39$ & 1.04 & 1.32 & 1.13 & 1.08 \\
\hline $40-49$ & 0.98 & 1.34 & 0.90 & 0.85 \\
\hline $50-59$ & 0.79 & 1.20 & 0.80 & 0.70 \\
\hline $60+$ & 0.84 & 0.92 & 0.68 & 0.61 \\
\hline \multicolumn{5}{|l|}{ Nivel de instrucción } \\
\hline Sin instrucción & 0.55 & 0.54 & 0.32 & 0.38 \\
\hline Primaria incompleta & 0.63 & 0.83 & 0.54 & 0.71 \\
\hline Primaria completa & 0.85 & 1.28 & 0.85 & 1.00 \\
\hline Secundaria y más & 1.22 & 2.05 & 1.37 & 1.65 \\
\hline Total & 0.98 & 1.16 & 0.95 & 0.86 \\
\hline Número de casos & 8899 & 6694 & 15222 & 1090 \\
\hline
\end{tabular}

Fuente: Enfes, 1987.

${ }^{20}$ La situación contraria parecería ser más frecuente: que los empleadores ofrezcan remuneraciones inferiores a mujeres y jóvenes solteros bajo el pretexto de que no tienen una familia a su cargo o bien, que sólo se trata de un ingreso complementario de otro principal. 
GRÁFICA 7

Distribución de los ingresos mensuales según el sexo y la condición de jefatura del hogar

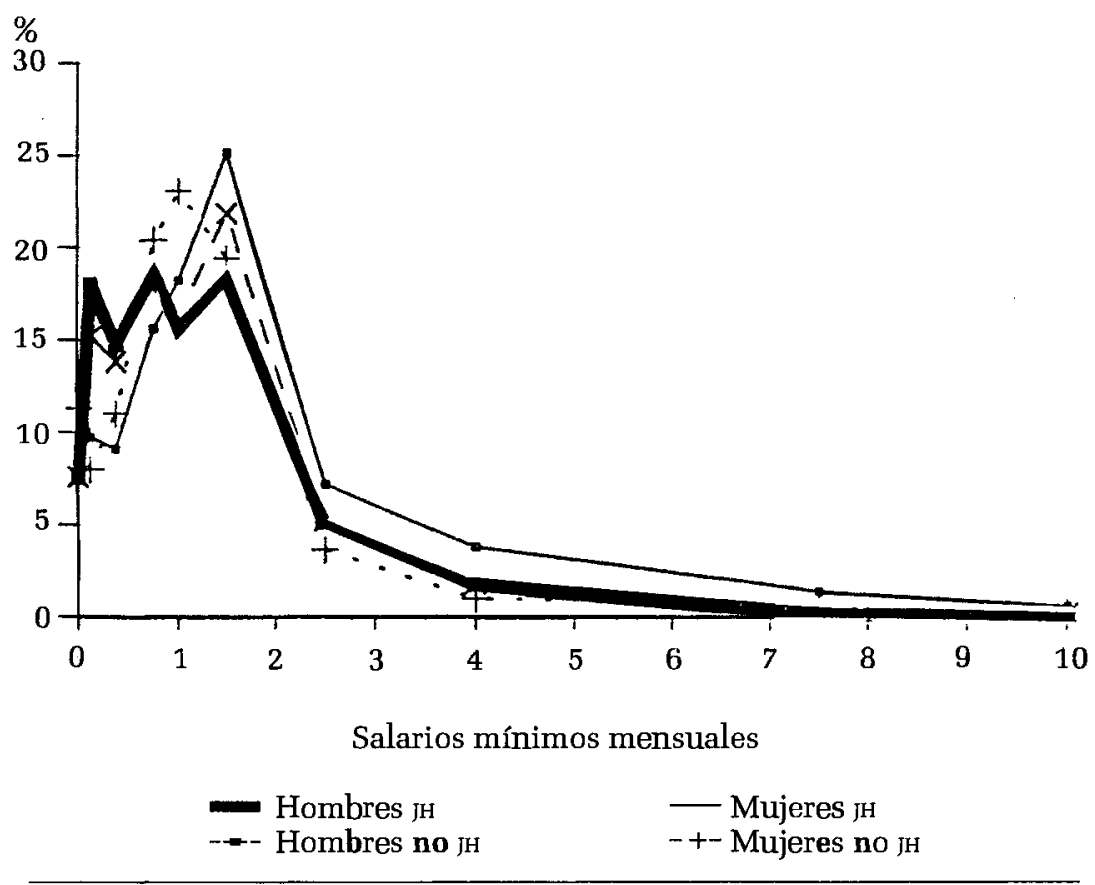

Fuente: Enfes, 1987.

Puede verse que la importancia del salario crece con el tamaño de la localidad de residencia, lo cual sin duda está relacionado con mayores posibilidades de empleo fuera del sector primario que ofrecen las zonas urbanas. Las desigualdades entre el ingreso de los jefes y los demás miembros de los hogares son mucho menos marcadas en el medio rural, así como en las edades extremas (menos de 30 y más de 50 años). Los jefes de hogar de treinta a cincuenta años de edad y los que residen en zonas urbanas son los mejor remunerados; ganan alrededor de $40 \%$ más que los no jefes. Para los demás miembros de los hogares, las desigualdades son menos importantes, pero puede decirse que en general las personas que residen en hogares nucleares perciben salarios más elevados que los que viven en hogares más complejos. 
Más que utilizar la medida de los ingresos del jefe y de los otros miembros, para aproximarse al nivel de bienestar de los hogares es esencial contar con una medida relativa de los ingresos por hogar. Nosotros lo haremos reuniendo los ingresos de todos los miembros que ejercen una actividad remunerada y dividiendo ese total entre el número de miembros. Los resultados de este cálculo se presentan en el cuadro 4.

\section{CUADRO 4}

Ingresos per capita de los hogares según el medio, la edad del jefe y el tipo del hogar, según el sexo del jefe

\begin{tabular}{lccc}
\hline $\begin{array}{l}\text { Ingresos mensuales / } \\
\text { salario mínimo }\end{array}$ & \multicolumn{2}{c}{ Sexo del jefe del hogar } & \\
& Hombre & Mujer & Total \\
\hline Medio de residencia & & & \\
$\quad$ Rural & 0.17 & 0.24 & 0.17 \\
Semiurbano & 0.17 & 0.25 & 0.18 \\
Urbano & 0.19 & 0.25 & 0.20 \\
Metropolitano & 0.20 & 0.27 & 0.21 \\
& & & \\
Edad del jefe del hogar & & & \\
15-29 & 0.25 & 0.28 & 0.25 \\
30-39 & 0.18 & 0.24 & 0.19 \\
40-49 & 0.15 & 0.21 & 0.16 \\
50-59 & 0.16 & 0.24 & 0.17 \\
60+ & 0.20 & 0.32 & 0.22 \\
Total & & & \\
Número de casos & 0.18 & 0.26 & 0.19 \\
& 6694 & 1090 & 7784 \\
\hline
\end{tabular}

Fuente: Enfes, 1987.

Aun si los jefes de hogar hombres perciben salarios más elevados que las jefas de hogar, los hogares dirigidos por mujeres se caracterizan por contar con ingresos per capita 30 a $40 \%$ más elevados que los hogares cuyo jefe es un hombre. Esta desigualdad es más acentuada en las localidades rurales y parecería estar en contradicción con las tesis que sostienen que los hogares dirigidos por mujeres se encuentran en condiciones más desfavorables (Buvinic, Youssef y Von Elm, 1978; Bruce y Kohn, 1986; Castro, 1987, 1991; Rosenhouse, 1990); de hecho, esta aparente contradicción es originada por la ausencia de una definición clara y unívoca de lo que es un jefe de hogar. La comparación de datos provenientes de fuentes en las que existe una autoidentificación 
de los jefes de hogar con otras donde la jefatura es definida por criterios preestablecidos trae consigo errores metodológicos y debe ser evitada.

La distinción por sexo es neta en lo que toca al tipo de ocupación de los jefes de hogar sin actividad remunerada. Cerca de tres de cada cuatro jefas de hogar se consagran a las tareas domésticas, mientras que uno de cada tres jefes hombres está retirado; uno de cada cuatro incapacitado y casi uno de cada cinco es trabajador no asalariado. Podría decirse, si las labores domésticas fuesen reconocidas como una actividad, que la proporción de jefas in activas es inferior a la de jefes hombres inactivos. Puede formularse entonces la hipótesis que los hogares con jefatura femenina deben poner en juego estrategias distintas al trabajo del jefe para conseguir recursos financieros y considerar al trabajo doméstico como un elemento importante de estas estrategias, dado que permite a otros miembros del hogar, especialmente mujeres, participar en la actividad económica.

\section{La composición de los hogares}

\section{El tamaño de los hogares}

Un elemento muy útil para ilustrar el ciclo de vida de los núcleos familiares es el tamaño de los hogares según el sexo y la edad del jefe del hogar. Se trata de un indicador básico en los estudios demográficos de la familia y ha sido utilizado como medida de la complejidad de los hogares, aun si no es el más adecuado (Burch, Lira y Lopes, 1976; Bongaarts, Burch y Wachter, 1987). En general, podemos decir que el tamaño de los hogares aumenta en las primeras etapas de la transición demográfica, como resultante de la disminución de la mortalidad y de la fecundidad elevada y constante; con la reducción de la fecundidad hay una tendencia a la disminución del tamaño de los hogares. Por otro lado, el tamaño tiene también una correlación positiva con la edad a la primera unión (Tuirán, 1993), pero sobre todo con la etapa del ciclo de vida del jefe. Al respecto, en la Enfes (cuadro 5) encontramos que para todos los jefes de hogar y en particular para los hombres, el número de personas por hogar alcanza su monto más elevado entre cuarenta y cincuenta años. Los hogares más grandes están dirigidos por jefes cuya edad no sobrepasa los cincuenta años. Los hogares dirigidos por una mujer son de tamaño más pequeño, alcanzando más o menos las tres cuartas partes del de aquéllos dirigidos por un hombre, cualesquiera que sean las categorías de 
edad del jefe de hogar considerados. Esto puede ser explicado por las diferentes etapas en el ciclo de vida: las jefas de hogar son sobre todo mujeres antes unidas, mientras que los jefes de hogar hombres viven casi todos en unión.

CUADRO 5

Tamaño promedio de los hogares, según la edad y el sexo del jefe del hogar

\begin{tabular}{lccc}
\hline $\begin{array}{l}\text { Edad del jefe del } \\
\text { hogar }\end{array}$ & \multicolumn{2}{c}{ Sexo del jefe del hogar } & \\
\cline { 2 - 3 } & Hombre & Mujer & Total \\
$15-29$ & 4.1 & 3.4 & \\
$30-39$ & 5.5 & 4.2 & 4.0 \\
$40-49$ & 6.5 & 4.8 & 5.4 \\
$50-59$ & 6.1 & 4.0 & 6.3 \\
$60+$ & 5.0 & 3.1 & 5.6 \\
& & & 4.5 \\
Total & 5.4 & 3.9 & 5.2 \\
Número & 6694 & 1090 & 7784 \\
\hline
\end{tabular}

Fuente: Enfes, 1987.

Las diferencias más importantes entre los tamaños de los hogares, dirigidos por hombres o por mujeres, se relacionan con los componentes de esos hogares (véase el cuadro 6). Así, si se descompone el tamaño, se ve que la ausencia de un cónyuge en los hogares dirigidos por una mujer y el número más reducido de hijos solteros explican en gran parte las desigualdades en la talla de los hogares. El hecho de que exista una proporción más grande de hogares extensos dirigidos por una mujer se explica por la presencia de más descendientes (hijos casados o antes unidos y nietos). El componente no nuclear de esos hogares es dos veces más importante que en los hogares dirigidos por los hombres, mientras que los otros lazos de parentesco están menos presentes.

\section{¿Quién reside con los jefes del hogar?}

En lo que respecta a los otros miembros de los hogares, nos ocuparemos de varias características: su pertenencia al núcleo central o a los núcleos periféricos, el tipo de extensión de estos últimos y las condiciones de vida de los hogares. La regla de residencia (virilocalidad o uxorilocalidad) de los núcleos periféricos 
CUADRO 6

Componentes del tamaño de los hogares según el sexo del jefe del hogar

\begin{tabular}{lccc}
\hline & \multicolumn{2}{c}{ Sexo del jefe del hogar } & \\
\cline { 2 - 3 } & Hombre & Mujer & Total \\
\hline Tamaño total & 5.4 & 3.9 & 5.2 \\
& & & \\
Componente nuclear: & 5.0 & 3.0 & 4.7 \\
$\quad$ hijos solteros & 3.1 & 2.0 & 2.9 \\
Componente no nuclear & 0.4 & 0.8 & 0.5 \\
Proporción nuclear & 92.6 & 76.9 & 90.1 \\
Número de casos & 6694 & 1090 & 7784 \\
\hline
\end{tabular}

Fuente: Enfes, 1987.

nos parece un elemento muy importante para acercarse a las relaciones al interior de los hogares. Considerando que las mujeres son la mayor parte del tiempo, responsables de la salud de los miembros del hogar, pensamos que las relaciones entre una madre y su hija casada son diferentes de aquellas que se establecen a raíz de la corresidencia de una suegra y su nuera.

La primera caracterización de los lazos de parentesco está construida en relación con los núcleos familiares: centrales, descendientes, colaterales y otros familiares, y se presenta en el cuadro 7. El lazo de parentesco más frecuente es el de padre con hijos aún solteros: representa $52.5 \%$ del total. Los jefes de hogar y sus cónyuges representan $34.9 \%$ de los padres y por consecuencia, solamente un miembro de la familia de cada ocho no pertenece al núcleo central.

Entre los parientes exteriores al núcleo central, el tipo de extensión más frecuente es, como ya lo hemos constatado, la vertical, y sobre todo, la descendencia por añadidura de un nuevo núcleo familiar debido al matrimonio de uno de los hijos. Entre los no solteros, no hay diferencias en relación con el sexo $(50.9 \%$ son hombres y $49.1 \%$ mujeres). Sin embargo, si se considera la condición de unión, resulta que los unidos son en su mayoría hombres $(60.5 \%)$, a pesar de la presencia más importante de hijas entre los exunidos (72.4\%). Se observa una virilocalidad: las nuevas parejas se quedan más frecuentemente con los padres del marido que con los padres de la mujer. Sin embargo, pareciera que los lazos de sangre son más fuertes y para muchas mujeres que interrumpen su unión, el regreso al hogar parental sería una solución prioritaria, índice de la solidaridad familiar. 
CUADRO 7

Distribución porcentual de los miembros de los hogares según el lazo de parentesco con el jefe, por sexo

\begin{tabular}{lrr}
\hline Lazo de parentesco & Hombres & Mujeres \\
\hline Jefe del hogar & 33.7 & 5.1 \\
Cónyuge & 0.2 & 30.2 \\
Hijo/a & 55.1 & 50.9 \\
Yerno/nuera & 1.2 & 1.9 \\
Nieto/a & 5.3 & 4.9 \\
Hermano/a & 1.3 & 1.0 \\
Cuñado/a & 0.4 & 0.6 \\
Padre/madre & 0.3 & 1.5 \\
Suegro/a & 0.1 & 0.5 \\
Otro lazo & 1.8 & 1.8 \\
Empleado/a & 0.1 & 0.9 \\
Sin lazo & 0.5 & 0.5 \\
Total & & 100.0 \\
Número de casos & 100.0 & 49026 \\
\hline
\end{tabular}

Fuente: Enfes, 1987.

En lo que respecta a los ascendientes, los más numerosos son las madres a causa de la sobremortalidad masculina. Entre los familiares colaterales, encontramos más hermanos y hermanas que cuñados o cuñadas. Asimismo, los sobrinos y las sobrinas están más frecuentemente ligados a los jefes de los hogares por un hermano o una hermana de aquél que por un cuñado o cuñada. Esto indicaría que las extensiones de los hogares tienen lugar más frecuentemente por medio de la familia del jefe que por la del cónyuge. Esto significa que la consanguineidad sería más importante que las alianzas para explicar la corresidencia.

Pero el lazo de parentesco con el jefe y el estatus de las personas dentro de los hogares están también relacionados con el ciclo de vida; en consecuencia, debemos considerar los indicadores que puedan mostrar al menos algunos aspectos del ciclo de vida. Pensamos, por supuesto, en la edad, pero también en la condición marital. Una vez que estas dos variables han sido consideradas, la dinámica de los lazos de parentesco es más clara. En la gráfica 8 hemos representado la población de los hogares (los residentes habituales) según su edad, su sexo y su lazo de parentesco, haciendo la diferencia entre hijos solteros, en unión y exunidos. No hemos incorporado la condición de unión a las otras categorías a causa del pequeño número de efectivos. La pirámide ilustra de manera muy 
clara los cambios de la posición en relación con el jefe del hogar que acompaña las diferentes etapas del ciclo de la vida: en los hombres, la entrada en unión está acompañada, en la mayoría de los casos, de la jefatura de sus hogares, mientras que para las mujeres aquello significa que se convierten en las esposas del jefe. La preferencia por la virilocalidad como regla de residencia está puesta en evidencia por la diferencia entre yernos e hijos unidos. Al mismo tiempo, la disminución de estos dos grupos atestigua la independencia residencial deseada por las nuevas parejas y que a veces es retardada. Por otro lado, se evidencian importantes diferencias entre los sexos: el desfase de las edades entre cónyuges, primeramente, y de manera más importante, la ausencia de concordancia entre las categorías; esto significa, salvo que los esquemas de matrimonios subsecuentes sean muy diferentes según el sexo, que el número de hijos exunidos debería ser similar al de las hijas ex-unidas. ¡Pero éste último es cuatro veces más grande que el correspondiente a los hombres! Esto podría significar que los hombres "borran" u "olvidan" más fácilmente su historia conyugal, pero atestigua también la dificultad de las mujeres para asumir su celibato y la soledad (en términos de ausencia de un cónyuge) y la autonomía en el marco de una sociedad patriarcal como la mexicana (Jelin, 1992). De la misma manera, el número de hijos unidos es 1.24 veces que el de nueras, y el de hijas unidas representa 1.41 veces el total de yernos. Más allá del aspecto anecdótico, estas constataciones nos previenen contra la utilización irreflexiva de la información sobre la condición marital tal como está declarada en el cuestionario de hogar. La condición de unión tiene un peso muy importante en la sociedad, lo que puede llevar a ciertas personas a afirmar situaciones que no corresponden a la realidad. Pero la disponibilidad de una lista de hogares nos permite resolver este problema verificando la presencia o ausencia de cónyuges en cada núcleo familiar, una vez que han sido identificados.

\section{Construcción de núcleos familiares}

Para llegar a la construcción de núcleos familiares a partir de la información contenida en los cuestionarios de hogar hemos utilizado las siguientes variables:21 a) el lazo de parentesco con el jefe del

21 Se debe subrayar que para la elaboración de núcleos familiares hemos seleccionado a los miembros del hogar que eran residentes habituales, es decir que hemos excluido a las personas que habían sido declaradas como temporalmente presentes. 
GRÁFICA 8

Distribución de la población según el sexo, la edad y el lazo de parentesco con el jefe del hogar

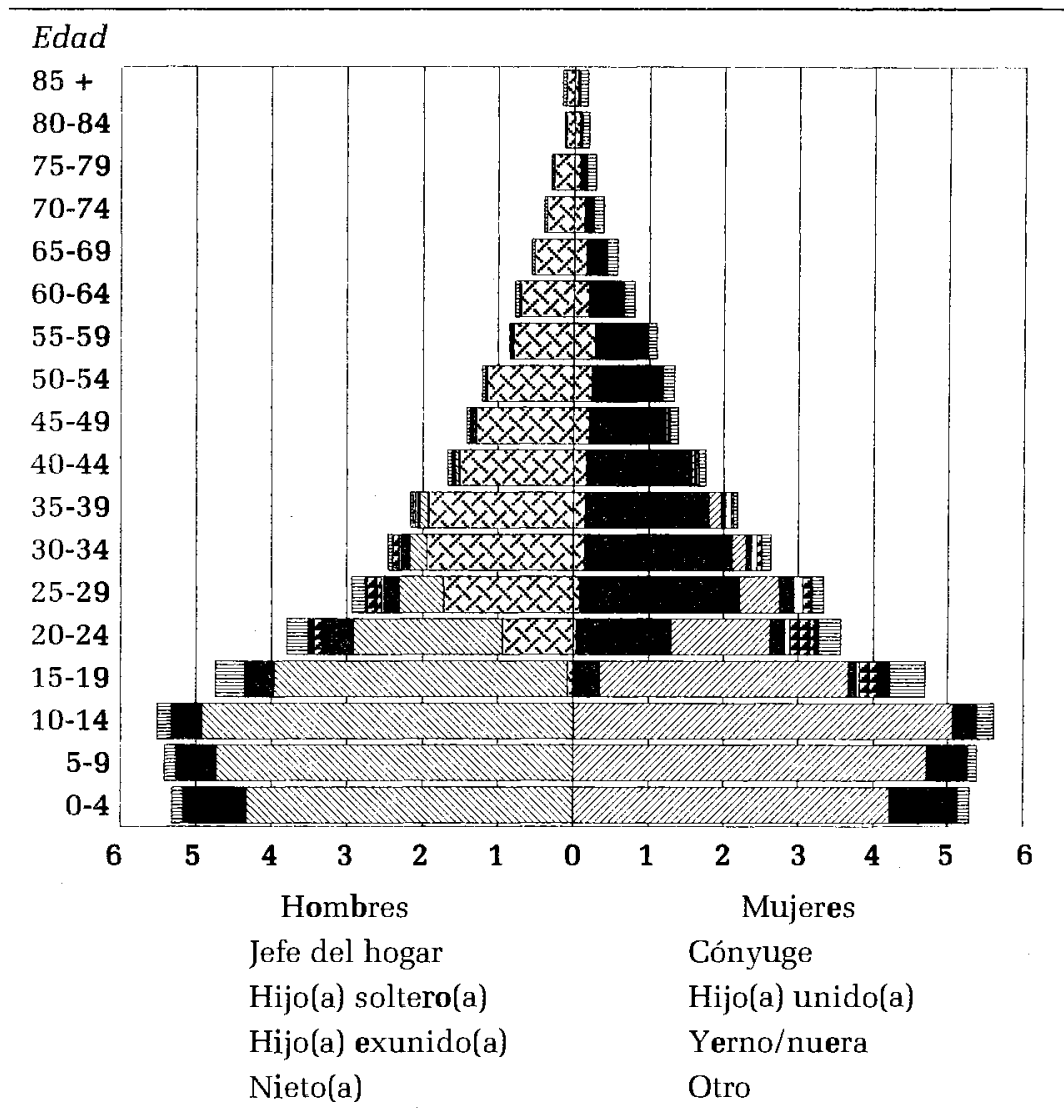

Fuente: Enfes, 1987; residentes habituales.

hogar; b) la persona de referencia (para el lazo de parentesco); c) la condición de residencia; $d$ ) el sexo y finalmente, e) el estado civil.

Luego procedimos a la división de los lazos de parentesco en siete categorías (cuadro 8). Para distinguir a los hijos solteros de los no solteros, hemos tomado en cuenta el estado conyugal; por un lado, los solteros, por otro, los enlazados por unión libre o casados; los viudos, divorciados o separados, así como la eventual presencia de nietos(as) del jefe de la persona de referencia, quien era una persona declarada como soltera. Una vez identificados los 
lazos de parentesco, podemos distinguir a los miembros de núcleo central (las tres primeras categorías) de los miembros de los núcleos periféricos (de la cuarta a la séptima categorías) y de los noemparentados. Puede constatarse el pequeño número de miembros del hogar que no pertenecen al núcleo central, lo que significa que en bastantes casos los hogares se identifican con las familias.

Para las personas que no pertenecen al núcleo familiar, los descendientes del jefe del hogar son los más numerosos. El tipo de extensión más común vincula a hijos casados y su núcleo. La presencia de ascendientes es menos frecuente que la de colaterales, y la más rara es aquélla de otros parientes (sólo un hogar sobre cincuenta).

Los no-parientes están presentes sólo en 3.7\% de los hogares y representan uno por ciento de la población. La presencia de los no-parientes, sobre todo de empleados domésticos, es ante todo un fenómeno urbano y su importancia se ha reducido mucho; 22 el oficio de empleado doméstico se vuelve cada día más una profesión y ya no una especie de tutela y de explotación del trabajo de jóvenes provenientes de medios muy desfavorecidos. La ausencia de aprendices muestra también la separación que existe entre la esfera del trabajo remunerado y la familiar.

\section{CUADRO 8}

Proporción de hogares según los lazos de parentesco presentes

\begin{tabular}{lc}
\hline Grupo de parentesco & Porcentaje \\
\hline Cónyuges & 79.8 \\
Hijos/as solteros/as & 78.2 \\
Descendientes: hijos/as no solteros/as, yernos/nueras, & \\
nietos/as y bisnietos/as y bisnietos/as & 15.2 \\
Ascendientes: padres, suegros/as, abuelos/as & 6.0 \\
Colaterales: hermanos/as, cuñados/as, sobrinos/as y & 7.7 \\
concuños/as & \\
Otros parientes: tíos/as, primos/as y otros lazos de parentesco, & 2.0 \\
$\quad$ diferentes o no especificados & 3.7 \\
No parientes & 7784 \\
Número de hogares &
\end{tabular}

Fuente: Enfes, 1987.

22 Según el censo de 1980, se enumeraron 913558 empleados domésticos, es decir, $2.11 \%$ de la población de 12 años y más. Para 1990, se reportan 272700 sirvientes, que representan $0.34 \%$ de la población residente en hogares. 


\section{Núcleos completos/incompletos}

Después de haber identificado el núcleo central, hemos procedido a la identificación de núcleos periféricos y a la clasificación de todos los núcleos en completos o incompletos. Hemos adoptado el procedimiento siguiente: para cada mujer de quince años o más 23 en unión, hemos verificado la presencia de un hombre en unión y su lazo de parentesco con dicha mujer (para una mujer jefe del hogar buscamos un cónyuge, para una cónyuge un jefe del hogar, por una hija un yerno, etc.). Una vez identificado el cónyuge de cada mujer, los dos eran señalados como constituyentes de un núcleo completo. Se clasificó como pertenecientes a un núcleo incompleto a las mujeres unidas a quienes no se pudo hallar una pareja corresidente, así como a las mujeres con una unión interrumpida.

En una segunda etapa, hemos retomado a los hombres en unión de quince años y más que no han sido identificados como pertenecientes a un núcleo completo y se ha buscado su eventual pareja entre las mujeres que aún no han sido identificadas. En algunos casos, sobre todo cuando los lazos de parentesco no son muy evidentes (nietos, sobrinos, otros familiares) y para las parejas cuyos miembros no tenían el mismo estado civil, hemos procedido a una revisión de la información concerniente al hogar en cuestión, para descubrir a las parejas que no podían ser identificadas automáticamente y corregir los eventuales errores de codificación.

Un caso particular es el de los jefes de hogar solteros $(4.8 \%$ del total): dado que los hogares se construyen alrededor de un núcleo central, se consideró a este último como incompleto, para evitar la existencia de hogares sin núcleo central.

Los resultados están consignados en el cuadro 9, el cual muestra la relativa simplicidad de los hogares mexicanos: $81.2 \%$ están constituidos por un solo núcleo familiar, de los cuales $67.1 \%$ por un solo núcleo completo y $14.1 \%$ por un núcleo incompleto. Se puede observar que entre los hogares que contienen más de un núcleo, el esquema de cohabitación más frecuente (35.1\% de los casos) es aquel donde se encuentra un núcleo completo al que se agrega un núcleo incompleto. La multiplicidad de núcleos se debe sobre todo a la presencia de núcleos incompletos. Esta primera información nos lleva a interrogarnos sobre la composición de esos núcleos.

${ }^{23}$ En el cuestionario de hogar de la Enfes sólo se preguntaba el estado civil a las personas de 15 años y más. 
CUADRO 9

Distribución porcentual de los hogares según el número de núcleos familiares completos e incompletos que los componen

\begin{tabular}{|c|c|c|c|c|}
\hline \multicolumn{5}{|c|}{ Núcleos } \\
\hline \multirow[b]{2}{*}{ Completos } & \multicolumn{3}{|c|}{ Incompletos } & \multirow{2}{*}{$\begin{array}{r}N=7784 \\
\text { Total }\end{array}$} \\
\hline & 0 & 1 & $2+$ & \\
\hline 0 & - & 14.1 & 4.1 & 18.2 \\
\hline 1 & 67.1 & 6.6 & 2.0 & 75.7 \\
\hline $2+$ & 1.9 & 3.0 & 1.3 & 6.1 \\
\hline Total & 69.0 & 23.7 & 7.4 & 100.0 \\
\hline
\end{tabular}

Fuente: Enfes, 1987.

Para esto, distingamos primero los núcleos centrales y los núcleos periféricos, separando los descendientes de los ascendientes, de los colaterales y de los otros parientes y haciendo la distinción entre núcleos completos y núcleos incompletos. Las extensiones (cuadro 10) se hacen frecuentemente por medio de núcleos incompletos: para los descendientes hay 1.4 veces más núcleos incompletos que completos, 18 veces más en los ascendientes y 3 veces más en los colaterales. Así aparece que cuatro de cada cinco hogares tienen su núcleo central completo y que alrededor de un hogar sobre diez tiene núcleos incompletos, compuestos de descendientes del jefe del hogar, contra un hogar sobre quince con núcleos completos.

CUADRO 10

Porcentajes del total de hogares incluyendo núcleos familiares completos e incompletos según el tipo

\begin{tabular}{lc}
\hline Tipo de núcleo & $N=7784$ \\
\hline Central completo & 79.8 \\
Central incompleto & 20.2 \\
Descendientes completos & 6.8 \\
Descendientes incompletos & 9.6 \\
Ascendientes completos & 0.3 \\
Ascendientes incompletos & 5.5 \\
Colaterales completos & 0.5 \\
Colaterales incompletos & 1.5 \\
Otros completos & 0.6 \\
Otros incompletos & 0.4 \\
\hline
\end{tabular}

Nota: los renglones son independientes, es decir, los porcentajes no pueden ser sumados pues cada hogar puede contener uno o más núcleos, completos o incompletos.

Fuente: Enfes, 1987. 
Los ascendientes, de mayor edad, son en su mayoría mujeres que han.estado en unión, lo que explica la predominancia de núcleos incompletos y lo que hace pensar que la extensión de los hogares tiene lugar principalmente de una manera vertical: se trata de padres que aceptan los núcleos familiares de sus hijos. A veces los ancianos son mantenidos por sus hijos, pero la cohabitación de núcleos colaterales es poco habitual. Ésta resulta frecuentemente de la disolución de uniones (viudez, separación o divorcio). La distancia con el jefe del hogar, en términos de grados de parentesco, parece ser también un obstáculo a la corresidencia. La rareza de otros núcleos, completos o incompletos, lo muestra claramente.

\section{Las condiciones de vida en los hogares}

Se ha tenido una primera impresión de las condiciones de vida en los hogares con la medida del ingreso por persona. Esta información tiene que relacionarse con otras medidas del bienestar familiar. Pensamos inicialmente en el tamaño de los hogares, que es en la mayoría de los casos el único indicador de las condiciones de vida, en el ámbito del hogar, utilizado en el análisis de la salud de los niños. Esta última es considerada como indicador de la competencia por los recursos. La hipótesis implícita sería que los ingresos por persona son más reducidos si los hogares son de mayor tamaño. Sin embargo, el análisis del tamaño de los hogares debe hacerse mediante medidas relativas. Hemos escogido la densidad de ocupación de viviendas como una medida relativa del tamaño de los hogares porque ella aparece en relación más estrecha con los mecanismos que determinan la exposición a los riesgos dentro del hogar. Igualmente, la infraestructura de los servicios y las características físicas en esas viviendas serán analizadas, siguiendo nuestro esquema conceptual, para terminar con un indicador relativo a la población adolescente: su escolarización en oposición al trabajo u otras actividades.

\section{La densidad de ocupación de viviendas}

Hemos definido la tasa de ocupación de la vivienda como la relación entre el número de residentes habituales del hogar y el número de cuartos en las viviendas. Se puede entonces hacer el cálculo en relación con el número total de cuartos. En el siguiente cuadro son presentados el tamaño promedio de diferentes tipos 
de hogares, los números promedio de cuartos y de recámaras ${ }^{24}$ por hogar, así como las relaciones entre el número de residentes habituales (RH) y el de cuartos y recámaras. La tasa de ocupación de la vivienda así obtenida para el conjunto de la población es elevada: 2.7 personas por recámara, y aún más elevada en las zonas rurales (3.6 personas).

El cuadro 11 muestra las disparidades entre los diferentes medios y según el sexo del jefe del hogar. El tamaño más grande de hogares no nucleares no va a la par con una tasa de ocupación más elevada, no obstante, ellos ocupan las viviendas con más recámaras. Los niveles elevados de ocupación, a menudo asociados con hogares extensos en el caso de México, están sobre todo presentes en el caso de hogares extensos con un núcleo central completo.

CUADRO 11

Tamaño promedio de los hogares, número promedio de cuartos y de recámaras por hogar y tasa de ocupación de las viviendas, según el medio de residencia y el sexo del jefe del hogar

\begin{tabular}{|c|c|c|c|c|c|c|}
\hline & $\begin{array}{l}\text { Tamaño } \\
\text { promedio }\end{array}$ & $\begin{array}{c}\text { Cuartos/ } \\
\text { Hogar }\end{array}$ & $\begin{array}{c}\text { Recám./ } \\
\text { Hogar }\end{array}$ & $\begin{array}{c}\text { RH } / \\
\text { Cuarto }\end{array}$ & $\begin{array}{c}\text { RH/ } \\
\text { Recám. }\end{array}$ & $\begin{array}{l}\text { Número } \\
\text { de casos }\end{array}$ \\
\hline \multicolumn{7}{|c|}{ Medio de residencia } \\
\hline Rural & 5.7 & 2.1 & 1.6 & 2.8 & 3.6 & 1878 \\
\hline Semiurbano & 5.5 & 2.7 & 1.9 & 2.1 & 2.9 & 1153 \\
\hline Urbano & 4.9 & 3.1 & 2.0 & 1.6 & 2.4 & 2794 \\
\hline Metropolitano & 4.8 & 3.1 & 2.1 & 1.5 & 2.3 & 1959 \\
\hline \multicolumn{7}{|c|}{ Sexo del jefe del hogar } \\
\hline Hombre & 5.4 & 2.7 & 1.9 & 2.0 & 2.8 & 6694 \\
\hline Mujer & 3.9 & 2.8 & 1.8 & 1.4 & 2.1 & 1090 \\
\hline Total & 5.2 & 2.7 & 1.9 & 1.9 & 2.7 & 7784 \\
\hline
\end{tabular}

RH: residentes habituales.

Fuente: Enfes, 1987.

${ }^{24}$ A propósito de los espacios físicos, en el cuestionario de hogar de la Enfes se hacían cuatro preguntas: 1) el número de recámaras en la vivienda;2) el número total de cuartos en la vivienda, sin tomar en cuenta el baño y la cocina; 3) si la vivienda disponía de un lugar para cocinar y si se utilizaba para otros fines; 4) si la vivienda disponía de un baño, al interior o al exterior pero en el mismo terreno. No se reunió ninguna información relacionada con la superficie total de la vivienda. 


\section{La calidad de las viviendas}

El estudio de los hogares se debe acompañar del examen del medio ambiente inmediato y del marco de vida de los miembros del hogar. Para el análisis de las condiciones materiales de las viviendas se han establecido dos índices que reflejan la infraestructura de los servicios presentes en las viviendas y las características físicas de la residencia. Se trata de índices dicotómicos que dan a cada hogar una calificación positiva ("buena" infraestructura de servicios o "buenas" características físicas) o negativa, cuando el hogar no reúne por lo menos dos de los indicadores tomados en consideración: la presencia de agua corriente, electricidad y desagües, para la infraestructura de servicios, el suelo hecho de materiales diferentes a tierra, la existencia de un lugar utilizado exclusivamente para cocinar y de un baño, para las características físicas. Somos conscientes de que la presencia de servicios no implica su utilización, aunque la de canalizaciones, por ejemplo, está forzosamente en relación con la pureza del agua distribuida, por lo que estos índices nos dan una idea de las condiciones de comodidad de los hogares, sin pretender establecer una clasificación de viviendas en función del equipo, de sus características materiales o del acceso a los servicios. Otra observación es que los dos modelos de regresión estudian las viviendas ocupadas por los hogares, es decir, hemos escogido analizar el marco de vida de cada hogar, incluso si la vivienda estuviera ocupada por varios hogares, ${ }^{25}$ antes que modelizar las condiciones de aquélla.

Siete variables están consideradas: cinco apuntan a las características del jefe del hogar -el sexo, la edad, el nivel de instrucción, la condición de unión y el ejercicio de un trabajo remunerado- y las otras dos controlan el medio del hábitat y el tipo de hogar. Con la primera variable considerada se quiere probar si los hogares dirigidos por un hombre viven en condiciones mejores que aquéllos dirigidos por una mujer. La segunda variable es la instrucción del jefe del hogar, y opera como variable de control del nivel socioeconómico de los hogares. Dada la relación generalmente observada entre la escolaridad, el tipo de actividad y el nivel de ingresos de la población, la categoría de referencia escogida es "estudios posprimarios". El ejercicio de un trabajo remunerado por el jefe del hogar corresponde a otra variable de control, tanto del estatus socioeconómico como del ciclo de vida 
del hogar; esta variable nos puede ayudar a considerar la doble significación de la jefatura de los hogares: una económica basada en la importancia de los ingresos y la otra cultural, basada en la jerarquía, resultado del respeto a los mayores.

La condición de unión y de la edad del jefe del hogar son indicadores de su ciclo de vida; las comparaciones de sus modalidades serán hechas en relación con los hogares dirigidos por los jefes o jefas casados o unidos y en relación con aquellos del grupo de 30 a 39 años. El medio de residencia es tomado como indicador de la disponibilidad de los servicios, siendo la categoría de referencia la de medios urbanos. Además, hemos retenido una variable representando la composición del hogar: los hogares nucleares, los hogares con extensión vertical y finalmente, una categoría residual, constituida por otros tipos de hogares.

Los dos modelos se han ajustado muy bien a los datos; el primero permite clasificar correctamente $85.8 \%$ de los hogares y el segundo $83 \%$. Los coeficientes de las dos ecuaciones se han presentado en el cuadro 12 . Uno de los resultados más importantes es que la variable "tamaño del hogar" no es significativa para ninguno de los dos modelos cuando los efectos de las otras variables están controladas. ${ }^{26}$ Las condiciones materiales de las viviendas son entonces independientes del número de miembros del hogar. La actividad económica es sólo débilmente significativa en el caso de la infraestructura de servicios y tiene el mismo efecto que en el de las características físicas de la vivienda: los hogares donde el jefe no ejerce ningún trabajo remunerado tienen posibilidades de residir en las viviendas presentando "buenas" condiciones materiales entre 20 y $30 \%$ más elevadas. Esto es, sin duda debido a la relación entre la edad de los jefes y sus condiciones de actividad económica: son los jefes de hogar de menor edad que trabajan y que regularmente no han tenido aún el tiempo ni los medios financieros para mejorar sus condiciones de vivienda.

Los coeficientes de las variables socioeconómicas tienen los signos esperados. Se encuentra una relación negativa entre el nivel de instrucción y los dos índices considerados: el hecho de haber terminado el ciclo primario sería el umbral entre las posibilidades de residir en viviendas en "buenas" o "malas" condiciones. La misma relación existe para el medio del hábitat, testigo de desigualdad en el acceso al equipamiento en los diferentes medios.

26 Con el deseo de presentar el modelo que mejor se ajustaba no hemos incluido los coeficientes correspondientes a la variable tamaño del hogar, ya que no se ha presentado como significativa. 
CUADRO 12

Coeficientes de regresión logística sobre los determinantes de la buena infraestructura de servicios (1) y de buenas características

físicas (2) de las viviendas ocupadas por los hogares

\begin{tabular}{|c|c|c|c|c|c|c|}
\hline \multirow{2}{*}{$\begin{array}{l}\text { (Referirse al texto } \\
\text { para la definición } \\
\text { de los índices) }\end{array}$} & \multicolumn{3}{|c|}{ (1) } & \multicolumn{3}{|c|}{ (2) } \\
\hline & $\beta$ & $e^{\bar{\beta}}$ & Sig & $\beta$ & $e^{\beta}$ & Sig \\
\hline \multicolumn{3}{|l|}{ Sexo del jefe del hogar } & $* * *$ & & & *** \\
\hline Hombre & & 1.0000 & & & 1.0000 & \\
\hline Mujer & 0.5760 & 1.7789 & & 0.4223 & 1.5254 & \\
\hline \multicolumn{3}{|l|}{ Grupos de edad del ${ }_{1 \mathrm{H}}$} & $* * *$ & & & $\star \star \star *$ \\
\hline $15-29$ & -0.7728 & 0.4617 & $* * *$ & -0.6258 & 0.5348 & $\star \star *$ \\
\hline $30-39$ & & 1.0000 & & & 1.0000 & \\
\hline $40-49$ & 0.5163 & 1.6758 & $* * *$ & 0.1253 & 1.1335 & \\
\hline $50-59$ & 0.7152 & 2.0446 & $\star * *$ & 0.5085 & 1.6627 & $\star \star \star *$ \\
\hline $60+$ & 0.8905 & 2.4363 & $\star \star \star ~$ & 0.2447 & 1.2773 & * * \\
\hline \multicolumn{3}{|c|}{ Nivel de instrucción del јн } & $* * *$ & & & $\star \star \star *$ \\
\hline Sin instrucción & -3.0084 & 0.0494 & $* * *$ & -2.1449 & 0.1171 & $* * *$ \\
\hline Primaria incompleta & -1.8313 & 0.1602 & $* * *$ & -1.3472 & 0.2600 & *** \\
\hline Primaria completa & -0.8195 & 0.4407 & $* * *$ & -0.4592 & 0.6318 & $* * *$ \\
\hline Secundaria y más & & 1.0000 & & & 1.0000 & \\
\hline \multicolumn{3}{|c|}{ Condición de unión del јн } & $* \star *$ & & & $\star \star \star$ \\
\hline Unido/a & & 1.0000 & & & 1.0000 & \\
\hline Exunido/a & -0.6602 & 0.5168 & *** & -0.5188 & 0.5953 & *** \\
\hline Soltero/a & -0.2862 & 0.7511 & * & -0.6649 & 0.5143 & *** \\
\hline \multicolumn{3}{|l|}{ Medio de habitat } & *** & & & *** \\
\hline Rural & -2.9935 & 0.0501 & *** & -2.3326 & 0.0970 & $\star \star \star$ \\
\hline Semiurbano & -0.5513 & 0.5762 & *** & -0.9508 & 0.3864 & *** \\
\hline Urbano & & 1.0000 & & & 1.0000 & \\
\hline Metropolitano & 1.7545 & 5.7806 & *** & 1.4093 & 4.0932 & $* \star *$ \\
\hline \multirow{2}{*}{\multicolumn{2}{|c|}{$\begin{array}{l}\text { Condición de actividad del } \mathrm{\mu H} \\
\text { Activo/a }\end{array}$}} & * & & & $\star *$ & \\
\hline & & 1.0000 & & & 1.0000 & \\
\hline Inactivo/a & 0.1840 & 1.2020 & & 0.2614 & 1.2987 & \\
\hline \multicolumn{3}{|l|}{ Tipo de hogar } & ** & & & 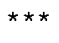 \\
\hline Nuclear & & 1.0000 & & & 1.0000 & \\
\hline Extensión vertical & 0.0625 & 1.0645 & & -0.0164 & 0.9837 & \\
\hline Otros tipos & 0.2913 & 1.3382 & ** & 0.3671 & 1.4435 & $\star * \star$ \\
\hline \multirow[t]{2}{*}{ Constante } & 1.2913 & & $* \star \star$ & 1.9120 & & $\star \star \star *$ \\
\hline & $X^{2}$ & & & $X^{2}$ & & \\
\hline-2 Log verosimilitud & 10310849 & & $* * *$ & 11207588 & & $* * *$ \\
\hline$X^{2}$ del modelo & 9770070 & & $* * *$ & 5936087 & & $* * *$ \\
\hline Bondad de ajuste & 14924294 & & $* * *$ & 14687244 & & $* * *$ \\
\hline Número de casos & 7771 & & & 7771 & & \\
\hline$\%$ bien estimado & 85.8 & & & 83.0 & & \\
\hline
\end{tabular}

Las categorias de referencia se indican en negritas.

Nivel de significación: ${ }^{*} \mathrm{p}<\mathbf{0 . 0 5} ;{ }^{* \star} \mathrm{p}<\mathbf{0 . 0 1} ;{ }^{* \star *} \mathrm{p}<\mathbf{0 . 0 0 1}$.

Fuente: Enfes, 1987. 
Si los resultados presentados anteriormente no son en absoluto sorprendentes, no así aquéllos que se refieren a las variables relativas a la estructura familiar. En primer lugar, la edad del jefe del hogar, indicador de la etapa en el ciclo de vida del hogar: esta variable es muy significativa en los dos modelos, pero los efectos son diferentes. Los momios de disponer de una buena infraestructura de servicios en la vivienda son claramente inferiores para los hogares donde el jefe no ha cumplido los 40 años y en el caso de las características de las viviendas, se observan efectos significativos para los jefes más jóvenes (menos de treinta años) que tienen la mitad de posibilidades que aquéllos de 30 a 39 años para residir en una vivienda presentando "buenas" características. En lo que respecta a la infraestructura de servicios, todos los grupos de edad son significativos, mientras que en lo referente a las características físicas, sólo lo es el de 40 a 49 años.

La condición de unión del jefe del hogar es también importante, tanto por la presencia de servicios, como por las condiciones materiales de la vivienda. Encontramos un efecto significativo de signo negativo para la infraestructura de servicios en la categoría de jefes exunidos, que sólo tienen $52 \%$ de probabilidades de residir en una vivienda provista de una "buena" infraestructura. En cuanto a los hogares dirigidos por un jefe soltero, sus probabilidades de habitar en una vivienda con "buenas" características son $25 \%$ inferiores a aquéllas de los jefes unidos.

Finalmente, la variable "tipo de hogar" es mucho más significativa en el caso de las características físicas que en el de la infraestructura de servicios. Para este último índice, el modelo nos indica que los otros tipos de hogares tienen riesgos relativos de habitar en viviendas presentando "buenas" condiciones superiores en $34 \%$ a aquéllos de los hogares "nucleares". Las posibilidades de este tipo de hogares de tener "buenas" características físicas son $44 \%$ superiores a los nucleares, pero se observa también que los hogares "extensos verticalmente" radican en viviendas presentando condiciones inferiores que la de aquéllas de los hogares nucleares. Sin embargo, es difícil obtener conclusiones definitivas de esos resultados, ya que la causalidad puede ser invertida; la disyuntiva es: las familias se reúnen en hogares compuestos porque disponen de viviendas con una buena infraestructura de servicios o es simplemente el hecho de reunir varios núcleos familiares lo que permite mejorar esas viviendas.

Además, ¿por qué las "extensiones verticales" -las más corrientes- tienen una relación inversa a las características físicas? Podemos invertir el sentido de la hipótesis o interrogar sobre la no-significancia de la relación estadística entre esta categoría de 
hogares y la infraestructura de servicios. ¿Sería tal vez porque el índice esté más en relación con las variables en el ámbito macro social, tales como la acción desigual del Estado frente a diferentes grupos sociales? En cambio, si se refiere a una variable en relación más directa con los comportamientos del hogar (las características físicas de la vivienda), la relación es significativa.

\section{Conclusiones}

Los resultados que hemos obtenido confirman la importancia de utilizar las variables que reflejan los efectos de la estructura familiar para el análisis de sus condiciones de vida. A propósito hemos utilizado estos indicadores en lugar de aquéllos más comunes y que se refieren a ciertas características del jefe del hogar (su nivel de instrucción o el tipo de actividad que ejerce), para evitar asignar las características del jefe a todos los miembros del hogar. Esta confusión conceptual, muy extendida, puede ser corregida utilizando los datos disponibles bajo otra óptica, tomando en cuenta la estructura familiar desde la formulación del marco conceptual.

¿Qué se puede obtener como conclusión de este trabajo? En primer lugar, la riqueza de las informaciones resultantes del análisis de datos recogidos por el cuestionario hogar. Los datos en el ámbito del hogar provenientes de encuestas demográficas del tipo EMF O DHS, han sido muy poco explotados, incluso ignorados, aunque pueden ayudarnos a comprender mejor los fenómenos demográficos y a ubicarlos mejor en el contexto social respectivo. No hemos querido desarrollar un análisis exhaustivo de los hogares, tal como lo propone Burch (1979); en cambio, preferimos enfocar nuestra atención sobre tres aspectos: la jefatura, la composición y las condiciones de vida de los hogares.

En lo que concierne a las características y la significación de la jefatura de los hogares, se pudo constatar que ésta está estrechamente ligada al ciclo de vida, pudiendo ser casi completamente explicada a partir del sexo, de la edad y de la condición marital de los individuos: la jefatura de los hogares es asunto de hombres casados mayores de 30 años o de mujeres con una unión interrumpida o de edad más avanzada. Esto no quiere decir que los atributos socioeconómicos, tales como el nivel de instrucción o la actividad no sean importantes: éstos también tienen efectos significativos, pero su impacto alcanza niveles más reducidos. Otro fenómeno importante relativo a la jefatura de los hogares en México es la ausencia de signos de nuclearización; encontramos más bien 
que la proporción de hogares nucleares es más elevada en el medio rural o entre individuos con grado escolar de primaria incompleta.

Por otro lado, nuestros resultados indican que es necesario matizar las hipótesis según las cuales los hogares dirigidos por mujeres se encuentran en condiciones inferiores a las de aquéllos encabezados por hombres. Esa versión puede provenir de generalizaciones que parten de estudios antropológicos, referidos sobre todo a medios urbanos, y que probablemente adolecen de confusiones metodológicas en lo que concierne a la definición de lo que es un hogar dirigido por una mujer (Rosenhouse, 1989). Generalmente, encontrar que los hogares dirigidos por mujeres están en condiciones económicas desventajosas es resultado de considerar su débil nivel de actividad, pero esto refleja una posición ideológica que identifica a la jefatura de un hogar con el soporte económico principal e ignora otras dimensiones, como la presencia constante (el proveedor principal puede haber emigrado y enviar dinero) o el ejercicio de la autoridad principal en el hogar. En los hogares con jefatura femenina, la ausencia de actividad económica de la jefa suele compensarse por una proporción más elevada de miembros del hogar que contribuyen a su sostén. Una conclusión importante es entonces la necesidad de considerar las dimensiones de la jefatura de los hogares diversas de la económica, tales como el nivel de autoridad y las relaciones de poder en el hogar.

El tema de las relaciones sociales dentro del hogar nos lleva al segundo de los aspectos tratados: la composición de los hogares; es decir, entre quiénes se dan esas relaciones de poder y de autoridad. El primer punto tratado es la relativa simplicidad de los hogares en México: sólo un miembro del hogar sobre ocho no pertenece al núcleo central; sin embargo, se han podido observar algunos rasgos característicos de la cohabitación en los hogares. Así, el esquema más común después del hogar nuclear es aquél extendido verticalmente, sobre todo a través de la virilocalidad de las nuevas parejas, pero también de una presencia importante de las hijas con una unión interrumpida. Esto implica, para un cierto número de casos, la corresidencia de mujeres en edad de procreación con sus madres o con sus suegras, lo cual implicaría, sobre todo con estas últimas, una relación de dependencia que puede tener, potencialmente, efectos diferentes sobre los comportamientos de estas mujeres.

Finalmente, el análisis de las condiciones de vida en las viviendas nos proporciona argumentos para rechazar la hipótesis de pretendidas condiciones desventajosas de hogares dirigidos por mujeres. No solamente la densidad de ocupación de viviendas es 
inferior, además, sus viviendas disponen de una mejor infraestructura de servicios y de mejores características físicas. Hemos obtenido algunos elementos que nos confirman las ventajas y las riquezas potenciales de un análisis profundo realizado en el ámbito de los hogares.

\section{Bibliografía}

Arizpe Schlosser, Lourdes (1975), Indígenas en la Ciudad de México. El caso de las "Marías", México, Secretaría de Educación Pública.

Arrom, Silvia (1985), The Women of México City: 1790-1857, Stanford, Stanford University Press.

Balán, Jorge, Harley Browning y Elizabeth Jelin (1977), El hombre en una sociedad en desarrollo. Movilidad geográfica y social en Monterrey, México, Fondo de Cultura Económica.

Bongaarts, John, Thomas K. Burch y Kenneth W. Wachter (eds.) (1987), Family Demography: Methods and their Applications, Oxford, Clarendon Press.

Borsotti, Carlos (1984), "Comentario a la Sesión Paralela V: Población, familia y desarrollo", en Memorias del Congreso Latinoamericano de Población y Desarrollo, México, El Colegio de México/UnAm/PISPAL, vol. 2, pp. 743-754.

Bruce, Judith y Marilyn Kohn (1986), Learning About Women and Urban Services in Latin America and the Caribbean. A Report on the Women, Low-Income Households and Urban Services Project of The Population Council, Nueva York, The Population Council.

Burch, Thomas K., Luis Felipe Lira y Valdecir Lopes (eds.) (1976), La familia como unidad de estudio demográfico, San José de Costa Rica, Celade.

Burch, T. K. (1979), "Household and Family Demography: a Bibliographic Essay", Population Index, vol. 45, núm. 2, p. 173.

Buvinic, Mayra, Nadia Yousseff y Barbara Von Elm (1978), Women Headed Households: the Ignored Factor in Development Planning, Washington, International Center for Research on Women.

Camposortega, Sergio (1988), L'analyse démographique de la mortalité au Mexique, 1940-1980, tesis de doctorado en Demografía, Lovainala-Nueva, Institut de Démographie, Université Catholique de Louvain.

Castro, Mary García (1987), "Mujeres pobres como jefes de hogar y como esposas en el proceso de reproducción en Bogotá: identidades y heterogeneidades", Documento de Trabajo WEP2-21/WP156, Ginebra, Programa de Políticas de Población y Trabajo, orr/вrr.

(1991), "Género, geraçao e raça: familias matrifocais pobres no Brasil", en El Poblamiento de las Américas, Veracruz, Uiesp/Somede/ABEP/PAA, vol. 3, pp. 369-408. 
De Vos, Susan (1987), "Latin American Households in Comparative Perspective", Population Studies, vol. 41, núm. 3, pp. 501-517.

- (1988), "The Socio-Economic Dimension in the Household Composition in Six Latin American Countries", Documento de Trabajo CDE/88-39, Madison (WI), Center for Demography and Ecology, University of Wisconsin.

Dirección General de Planificación Familiar (DGPF) (1988a), Encuesta Nacional sobre Fecundidad y Salud. Memoria de la reunión celebrada el 18 de febrero de 1988, México, DGPF/ssa.

(1988b), Encuesta Nacional sobre Fecundidad y Salud. Memoria de la reunión celebrada el 30 de septiembre de 1988, México, DGPF/sSA.

- e Institute for Resource Development (IRD) (1989), México. Encuesta Nacional sobre Fecundidad y Salud, 1987, México-Columbia (Maryland).

Echarri Cánovas, Carlos Javier (1989), Encuesta Nacional sobre Fecundidad y Salud 1987: una evaluación de la calidad de la información, tesis de maestría en Demografía, México, cEDDu-El Colegio de México.

(1991), "Familia, hogar y utilización de servicios de salud: el caso de México", en Proceedings of the Demographic and Health Surveys World Conference, Washington D.C., 1991, Columbia, Maryland, IRD/Macro International, Inc., vol. 3, pp. 1759-1781.

García, Brígida y Orlandina de Oliveira (1990), "Cambios en la presencia femenina en el mercado de trabajo: 1976-1987", ponencia presentada en la IV Reunión Nacional sobre Investigación Demográfica en México, México, Somede.

- - Humberto Muñoz y Orlandina de Oliveira (1982), Hogares y trabajadores en la ciudad de México, México, El Colegio de México /UNAM.

- (1983), Familia y mercado de trabajo. Un estudio de dos ciudades brasileñas, México, El Colegio de Móxico/unam.

Ham, Roberto (1993), "Envejecimiento demográfico y seguridad social. La insuficiencia de las pensiones por vejez", Demos. Carta demográfica sobre México, núm. 6, pp. 28-29.

Halli S. Shiva y K. Vaninandha Rao (1992), Advanced Techniques of Population Analysis, Nueva York, Plenum Press.

Izazola, Haydea (1992), "Hogares, familia y salud. Una aproximación a su relación con datos de la Encuesta Nacional de Fecundidad y Salud", Documento de Trabajo DT 7-1992, México, Centro de Estudios en Población y Salud.

__ y Ma. de la Paz López (1990), "Algunas características de los hogares según datos de la ENIGH 1984", ponencia presentada en la IV Reunión Nacional sobre Investigación Demográfica en México, México, Somede.

Jelin, Elizabeth (1978), "La mujer y el mercado de trabajo urbano", Estudios CEDES, vol. 1, núm. 6 .

(1984), "Familia, unidad doméstica y división del trabajo (¿qué sabemos?, ¿hacia dónde vamos?)”, en Memorias del Congreso Latino- 
americano de Población y Desarrollo, México, unam/ El Colegio de México/PISPAL, vol. 2, pp. 645-674.

(1991), "Family and Household: Outside World and Private Life", en Elizabeth Jelin (ed.), Family, Household and Gender Relations in Latin America, Londres-París, Kegan Paul International/Unesco, pp. 12-39.

(1992),"Celibacy, Solitude and Personal Autonomy: Individual Choice and Social Constraints", en Elza Berquó y Peter Xenos (eds.), Family Systems and Cultural Change, International Studies in Demography, Oxford, Clarendon Press, pp. 109-124 (Publicado en español en 1989 como "El celibato, la soledad y la autonomía personal: elección personal y restricciones sociales", Estudios Demográficos y Urbanos, vol. 4, núm. 1, pp. 117-138).

y Gustavo Paz (1991), "Familia / género en América Latina: cuestiones históricas y contemporáneas", en El poblamiento de las Américas, Veracruz, UIESP/ABEP/FCD/PAA/PROLAP/Somede, vol. 2, pp. 41-69.

Kuznesof, Elizabeth A. y Robert Oppenheimer (1985), "The Family and Society in Nineteenth-Century Latin America: an Historiographical Introduction", Journal of Family History, vol. 10, núm. 3.

Lacombe, B. y M.J. Lamy (1989), "Le ménage et la famille restreinte, illusion méthodologique de la statistique et de la démographie d'enquête", Cahiers des Sciences Humaines, vol. 25, núm. 3, pp. 407-414.

Lerner, Susana y André Quesnel (1982), "Una familia como categoría analítica en los estudios de población", Investigación demográfica en México, 1980, México, Conacyt, pp. 570-592.

Lira, Luis Felipe (1977), "Estructura familiar, población y fecundidad en América Latina. Análisis de algunos estudios", Notas de Población, Celade, núm. 13.

Lomnitz, Larissa (1975), Cómo sobreviven los marginados, México, Siglo XXI. y Marisol Pérez Lizaur (1982), "Significados culturales y expresión física de la familia en México", en Investigación demográfica en México, 1980, México, Conacyt, pp. 593-600.

(1991), "Dynastic Growth and Survival Strategies: the Solidarity of Mexican Grand-Families", en Elizabeth Jelin (ed.), Family, Household and Gender Relations in Latin America, Londres-París, Kegan Paul International/Unesco, pp. 123-132.

López, Ma. de la Paz y Raúl González (1989), "Estructura y composición de los hogares en los censos de población", en Memorias de la Tercera Reunión Nacional sobre la Investigación Demográfica en México, 1986, México, unam/Somede, vol. 1, pp. 683-696.

Malinowski, Bronislaw (1971), La vida sexual de los salvajes del noroeste de la Melanesia, Madrid, Ediciones Morata ( $1^{\mathrm{a}}$ ed. en inglés Londres, Routledge \& Kegan Paul, 1929).

Menéndez, Eduardo L. (1982), Medios de comunicación masiva, reproducción familiar y formas de medicina "popular", México, Centro de Investigaciones y Estudios Superiores en Antropología Social (Cuadernos de La Casa Chata, 57).

Murdock, George P. (1949), Social Structure, Nueva York, The MacMillan Company (trad. fr. Payot, París, 1972). 
Norušis, Marija J./SPSS Inc. (1986), SPSS/PC+ for the IBM PC/XT/AT, sPss Inc., Chicago Illinois.

(1990), SPSS/PC+ Advanced Statistics for the IBM PC/XT/AT and $P S / 2$, SPSS Inc., Chicago Illinois.

Oliveira, Orlandina de y Brígida García (1990), "Expansion of Female Labor Force and Social Transformation in México: 1950-1987", México, El Colegio de México (mimeo).

_ y Vania Salles (1989), "Acerca del estudio de los grupos domésticos: un enfoque sociodemográfico", en Orlandina de Oliveira et al. (comps.), Grupos domésticos y reproducción cotidiana, México, Coordinación de Humanidades-unam/El Colegio de México/Grupo Editorial Miguel Angel Porrúa, pp. 11-36.

Ono-Osaki, Keiko (1991), "Female-Headed Household in the Developing Countries: by Choice or by Circumstances?", en Proceedings of the Demographic and Health Surveys World Conference, Washington D.C., 1991, Columbia, Maryland, IRD/Macro International, vol. 3, pp. 1603-1621.

Pilon, Marc (1991), "De l'intéret du ménage pour la démographie de la famille", en Conference Femme, famille et population, 24-29 abril 1991, Ougadougou, Burkina Faso, UEPA.

Quilodrán, Julieta (1985), "Modalités de la formation et évolution des unions en Amérique Latine", en Congrès International de la Population, Florence, 1985, Lieja, Ordina, vol. 3, pp. 269-284.

- (1991), Niveles de fecundidad y patrones de nupcialidad en México, México, El Colegio de México.

Rosenhouse, Sandra (1989), "Identifying the Poor. Is «Headship» a Useful Concept?", Documento de Trabajo wp/58, Washington, Living Standards Measurement Study, The World Bank.

Tabutin, Dominique y Françoise Bartiaux (1986), "Structures familiales et structures sociales dans le Tiers-Monde", en Les familles d'aujourd'hui. Démographie et évolution récente des comportements familiaux, Coloquio de Ginebra, 17-20 septiembre 1984, París, Aidelf, pp. 231-243.

Torrado, Susana (1981), "Estrategias familiares de vida en América Latina: la familia como unidad de investigación censal", en Notas de Población, núm. 26, pp. 55-106.

Tuirán, Rodolfo (1993), "Vivir en familia: hogares y estructura familiar en México, 1976-1987", Comercio Exterior, vol. 43, núm. 7, pp. 662676.

Wong, Rebeca y Ruth E. Levine (1992), "The Effect of Household Structure on Woman's Economic Activity and Fertility: Evidence from Recent Mothers in Urban Mexico", Economic Development and Cultural Change, vol. 41, núm. 1, pp. 89-102. 
